\title{
The Role of Steroid Hormones in the Modulation of Neuroinflammation by Dietary Interventions
}

\author{
Andrea Rodrigues Vasconcelos ${ }^{1,2+}$, João Victor Cabral-Costa ${ }^{2 \dagger}$, \\ Caio Henrique Mazucanti ${ }^{1+}$, Cristoforo Scavone ${ }^{1}$ and Elisa Mitiko Kawamoto ${ }^{2 *}$
}

'Laboratory of Molecular Neuropharmacology, Department of Pharmacology, Institute of Biomedical Science, University of São Paulo, São Paulo, Brazil, ${ }^{2}$ Laboratory of Molecular and Functional Neurobiology, Department of Pharmacology, Institute of Biomedical Science, University of São Paulo, São Paulo, Brazil

OPEN ACCESS

Edited by: Gaetano Santulli, Federico II University, Italy

Reviewed by:

Stuart Maudsley,

Vlaams Instituut voor Biotechnologie, Belgium

Liana Asatryan,

University of Southern California, USA

${ }^{*}$ Correspondence: Elisa Mitiko Kawamoto kawamotoe@gmail.com

${ }^{\dagger}$ Andrea Rodrigues Vasconcelos, João Victor Cabral-Costa, and Caio Henrique Mazucanti have contributed equally to this work.

Specialty section: This article was submitted to Cellular Endocrinology, a section of the journal Frontiers in Endocrinology

Received: 30 November 2015 Accepted: 21 January 2016 Published: 04 February 2016

Citation:

Vasconcelos AR, Cabral-Costa JV, Mazucanti $\mathrm{CH}$, Scavone $\mathrm{C}$ and Kawamoto EM (2016) The Role of Steroid Hormones in the Modulation of Neuroinflammation by Dietary Interventions.

Front. Endocrinol. 7:9. doi: 10.3389/fendo.2016.00009
Steroid hormones, such as sex hormones and glucocorticoids, have been demonstrated to play a role in different cellular processes in the central nervous system, ranging from neurodevelopment to neurodegeneration. Environmental factors, such as calorie intake or fasting frequency, may also impact on such processes, indicating the importance of external factors in the development and preservation of a healthy brain. The hypothalamic-pituitary-adrenal axis and glucocorticoid activity play a role in neurodegenerative processes, including in disorders such as in Alzheimer's and Parkinson's diseases. Sex hormones have also been shown to modulate cognitive functioning. Inflammation is a common feature in neurodegenerative disorders, and sex hormones/ glucocorticoids can act to regulate inflammatory processes. Intermittent fasting can protect the brain against cognitive decline that is induced by an inflammatory stimulus. On the other hand, obesity increases susceptibility to inflammation, while metabolic syndromes, such as diabetes, are associated with neurodegeneration. Consequently, given that gonadal and/or adrenal steroids may significantly impact the pathophysiology of neurodegeneration, via their effect on inflammatory processes, this review focuses on how environmental factors, such as calorie intake and intermittent fasting, acting through their modulation of steroid hormones, impact on inflammation that contributes to cognitive and neurodegenerative processes.

Keywords: glucocorticoids, sex hormones, dietary energy restriction, high-fat diet, neuroinflammation

Abbreviations: 11 $\beta$-HSD2, 11beta-hydroxysteroid dehydrogenase type 2; AP-1, activator protein-1; A $\beta$, amyloid $\beta$; BBB, blood-brain barrier; BMI, body mass index; CNS, central nervous system; COX, cyclooxygenase; CR, calorie restriction; $\mathrm{CRH}$, corticotrophin-releasing hormone; DER, dietary energy restriction; EAE, experimental autoimmune encephalomyelitis; ER, estrogen receptor; GR, glucocorticoid receptor; HFD, high-fat diet; HPA, hypothalamic-pituitary-adrenocortical; HPG, hypothalamic-pituitary-gonadal; IкB- $\alpha$, inhibitor of nuclear factor kappa-B; IF, intermittent fasting; IFN- $\gamma$, interferon gamma; IKK, inhibitor of nuclear factor kappa-B kinase; IL, interleukin; iNOS, inducible nitric oxide synthase; JNK, c-jun N-terminal kinase; LB4, leukotriene B4; LB5, leukotriene B5; LPS, lypopolysaccharide; MR, mineralocorticoid receptor; NF- $\mathrm{B}$, nuclear factor kappa-B; NO, nitric oxide; OVX, ovariectomized; PGE2, prostaglandin E2; PGE3, prostaglandin E3; PUFA, polyunsaturated fatty acids; PVN, paraventricular nucleus; SHBG, sex hormone-binding globulin; TLR, toll-like receptor; TNF- $\alpha$, tumor necrosis factor-alpha. 


\section{INTRODUCTION}

Obesity is now considered a worldwide epidemic, with up to $35 \%$ of adults being considered overweight or obese. Women are more likely to develop such a phenotype (1), with female rates of obesity in the United States rising from $31.5 \%$ of women aged 60 or older in $2003-2004$ to $38.1 \%$ in 2011-2012 (2). Obesity is highly correlated with inflammation in many tissues, including the central nervous system (CNS) (3). Obesity and nutrient overload can trigger proinflammatory cytokines, such as tumor necrosis factor-alpha (TNF- $\alpha$ ) and interleukin (IL)- $1 \beta$, to build up in a number of affected tissues. Cells, including adipocytes and brain cells, respond to this metabolic stimulus through activation of different signaling pathways, including c-jun $\mathrm{N}$-terminal kinase (JNK), inhibitor of nuclear factor kappa-B kinase (IKK), and the nuclear factor kappa-B (NF- $\mathrm{kB}$ ) itself (3).

Diet plays a central role in obesity development, and a consensus on its exact influence is far from being defined. One way of seeing the effects of diet-related factors on obesity is evaluating leptin levels in the blood. Leptin resistance is a very common characteristic of obesity (4), and its serum levels are higher in obese humans when compared to healthy subjects (5). Regarding dietary intake, different factors affect leptin concentration and sensitivity differently, although several contradictory results can be found in the literature.

Regarding carbohydrate consumption, data are somewhat conflicting. While high glycemic index carbohydrate consumption or drastic high-carbohydrate diet ( $80 \%$ carbohydrate) may lead to leptin resistance $(6,7)$, different high-carbohydrate diets have no or the opposite effects on leptin sensitivity and blood concentrations $(8,9)$. On the other hand, fat intake has consistently been proven to be associated with a leptin resistance state $(10,11)$. There is, however, a divergence regarding the type of fat [saturated, mono, or polyunsaturated fatty acids (PUFA)] that is important for the effects on leptin levels $(12,13)$.

Accumulating data clearly show that a high-fat diet (HFD) negatively impacts on health, including increasing the incidence of cardiovascular diseases, diabetes, and overall mortality (14-16). HFD-exposed animals and humans also have an increased susceptibility to the development of a range of psychiatric disorders, which significantly correlates with body mass index (BMI) and obesity (17). Although BMI is widely used as an easy assessment of overall adiposity, studies show that abdominal fat deposition and visceral adiposity correlate more highly with metabolic (18) and psychiatric disorders (19). In that sense, another type of assessment, such as waist circumference and/or waist-to-hip ratio, is being used as a more relatable measurement that associates body fat and health disorders (18). Such correlation is greater in women than in men, which may indicate a difference between male and female responses to nutritional status in relation to mental health $(20,21)$.

On the other hand, dietary energy restriction (DER), achieved through a variety of protocols in which food intake is chronically or intermittently limited, can induce many beneficial outcomes, including via anti-inflammatory and antioxidant effects, that potentially increase lifespan [reviewed in Ref. (22)]. A wide body of data show food availability to affect both the activation and the rhythmicity of the hypothalamic-pituitary-adrenocortical (HPA) axis $(23,24)$. Furthermore, glucocorticoids, a group of steroid hormones, can modulate a plethora of processes in the organism, including immune function and energy metabolism (25-27). Therefore, the involvement of the HPA axis, especially of the glucocorticoid, rodent corticosterone (human cortisol), in the beneficial effects of DER has been extensively studied. Not only may DER modulate the HPA axis but it may also influence the hypothalamic-pituitary-gonadal (HPG) axis (28-32), thereby potentially interfering with the levels of sex hormones, such as androgens and estrogens.

The levels of both glucocorticoids and sex hormones seem to be strongly associated with inflammatory processes $(26,33-37)$. Therefore, this review focuses on assessing the role of these steroid hormones in neuroinflammation and the modulation exerted by dietary interventions such as HFD and DER on this process.

\section{NEUROINFLAMMATION AND STEROIDAL HORMONES}

\section{Glucocorticoids}

Many studies have shown that glucocorticoids exert antiinflammatoryeffectsin the organism (38). Glucocorticoids secreted by the adrenal glands after a physiological or psychogenic stressful stimulus promote anti-inflammatory and immunosuppressant actions through several genomic and non-genomic mechanisms, including the increase of anti-inflammatory gene expression (e.g.,

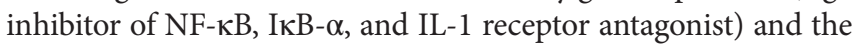
inhibition of NF- $\mathrm{KB}$ and of proinflammatory cytokines (e.g., TNF$\alpha$ and IL-1 $\beta)(37,39-41)$. These mitigating effects on inflammation are frequently exploited in clinical settings to treat a plethora of inflammatory and immune conditions $(42,43)$.

The synthesis of glucocorticoids and proinflammatory cytokines are interconnected via autoregulatory feedback loops, with corticosterone inhibiting the synthesis of proinflammatory cytokines and these cytokines stimulating the release of glucocorticoids through the upregulation of adrenocorticotropic hormone release from the pituitary gland $(38,44)$. Glucocorticoids levels are elevated after an inflammatory stimulus, including when induced by lipopolysaccharide (LPS) (45). Interestingly, disrupting the glucocorticoid signaling, by adrenalectomy or using glucocorticoid receptor (GR) antagonists, results in a much higher sensitivity of mice to the lethal effects of LPS (33, 46-51). As such, glucocorticoids are important for the resolution of inflammatory processes.

However, unlike the acute anti-inflammatory properties of, and protection afforded by, glucocorticoids, chronically elevated glucocorticoid levels are harmful, including in the CNS (52). Glucocorticoids can actually potentiate, rather than blunt, neuroinflammation (52-56). Over evolution, it is clear that stressful events may be accompanied by an immunological challenge, such as from tissue damage, with glucocorticoid-induced immune suppression, in such circumstances, being maladaptive (35).

Munhoz et al. (53) showed that elevated acute corticosterone levels are proinflammatory in the CNS, enhancing LPS-induced NF- $\mathrm{\kappa B}$ activation and proinflammatory gene expression, which 
is prevented by GR antagonist treatment. In another study, high corticosterone levels induced by chronic stress increase the TNF- $\alpha$ release and microglia activation induced by intracortical LPS injection, in a GR-dependent manner (52). Importantly, in this study, this reactivation-enhancing effect of glucocorticoids occurred even when the chronic stress occurred after the inflammatory stimulus. Furthermore, various studies have demonstrated that glucocorticoids increase the vulnerability of neurons to numerous insults, such as excitotoxins and global ischemia, rising neuronal death and worsening neurological outcomes (54-56).

It is important to note that glucocorticoids can have differential impacts on brain immunity in different brain regions. For instance, the glucocorticoid-mediated potentiation of the inflammatory markers induced by LPS occurs in the frontal cortex and hippocampus but with the opposite effect being evident in the hypothalamus (57). Thus, glucocorticoids increase or decrease CNS inflammation depending on the dose, timing, duration of glucocorticoid exposure, and the type of glucocorticoid compound (35). The precise mechanism that contributes to these paradoxical responses, although of the utmost importance, is still unknown. What is currently known is that whether glucocorticoids exert anti- or proinflammatory effects is context-dependent, with variable response dependent upon concentration, time of exposure, the compound type, and the nature of the stimulus [reviewed in Ref. (35)]. The glucocorticoid-mediated effects on inflammation under physiological and chronic stress are summarized in Figure 1.

\section{Sex Hormones}

The association of sex hormones and inflammation markers has been widely discussed in the literature. For instance, levels of testosterone and sex hormone-binding globulin (SHBG) were inversely correlated to markers of metabolic syndrome (58) and inflammation [e.g., C-reactive protein (59), $\gamma$-glutamyl transferase (60), and white blood cell and granulocyte count (36)]. Interestingly, male-derived cortical astrocytes show increased IL-6, TNF- $\alpha$, and IL- $1 \beta$ mRNA levels in comparison to femalederived cells (61), indicating the importance of androgens as a modulator of central inflammation.

This correlation has also been supported by pharmacological approaches. Jayaraman et al. (62) observed that treatment with testosterone in vitro suppressed the increase in TNF- $\alpha$ expression in glial cultures from the cortices of animals submitted to a HFD. In addition, they observed a similar effect in vivo in gonadectomized mice, with a testosterone-mediated rescue of TNF- $\alpha$ and IL- $1 \beta$ mRNA levels in the cortex. Similarly, Khosla et al. (63) found an increase in serum TNF- $\alpha$ levels induced by acute, chemically induced hypogonadism in men. This effect was partially rescued by treatment with estrogen or testosterone, with a complete rescue being achieved by a combined therapy of both hormones (63). Accordingly, orchidectomized animals challenged with LPS show increased sickness behavior and increased levels of circulating IL-6 (64). This augmented reaction to LPS might be mediated by increased toll-like receptor (TLR)-4 signaling, as treatment with testosterone in vitro and in vivo decreases TLR-4 expression and sensitivity in macrophages (64). Testosterone also has a similar protective effect, in comparison with estradiol, in primary cultured neurons, where it prevents serum deprivation-induced apoptosis in an aromatase-independent manner, eliminating a possible indirect effect mediated by its conversion into estrogen (65).

In addition, testosterone is a potential neuroprotective factor against the inflammation associated with neurodegenerative disorders, such as Alzheimer's disease (66) and multiple sclerosis (67). However, this literature is confounded by mixed results, with studies showing either no (60) or a positive correlation of testosterone levels and inflammation markers (68). As well as testosterone, estrogens have also been depicted as neuroprotective and/or anti-inflammatory agents. In microglia, estradiol has a very prominent inhibitory effect. Six hours after a subcutaneous injection of estradiol in ovariectomized (OVX) rats, LPS-induced macrophage activation is reduced by $60-90 \%$ in the cerebral cortex and hippocampus, as measured by reduced expression of ED-1/CD68. Similarly, in a mouse model of Alzheimer's disease with plaque deposition, activated microglia surrounding amyloid plaques are greatly increased in OVX mice, which is reversed by an estradiol replacement therapy, although no effects over $\mathrm{A} \beta$ deposit levels were observed (69). Accordingly, an in vitro study showed similar estrogen effects, impairing microglial activation. The estrogens, estriol, and estradiol, as well as progesterone, suppress LPS-induced increase in inducible nitric oxide synthase (iNOS) expression and nitrite production in N9 microglial cells and in rat primary cultured microglia $(70,71)$. Estradiol was able to suppress nitric oxide (NO) and TNF- $\alpha$ increase, as well as cell death, in rat primary cultured glial cells challenged with LPS (72). Additionally, by stimulating BV-2 murine microglial cells with LPS, Baker et al. (73) showed estrogen pretreatment to decrease NO production, as well as iNOS and cyclooxygenase (COX)-2 expression, through interaction with the estrogen receptor (ER)- $\beta$ (73). Albeit acute microglial activation could be essential

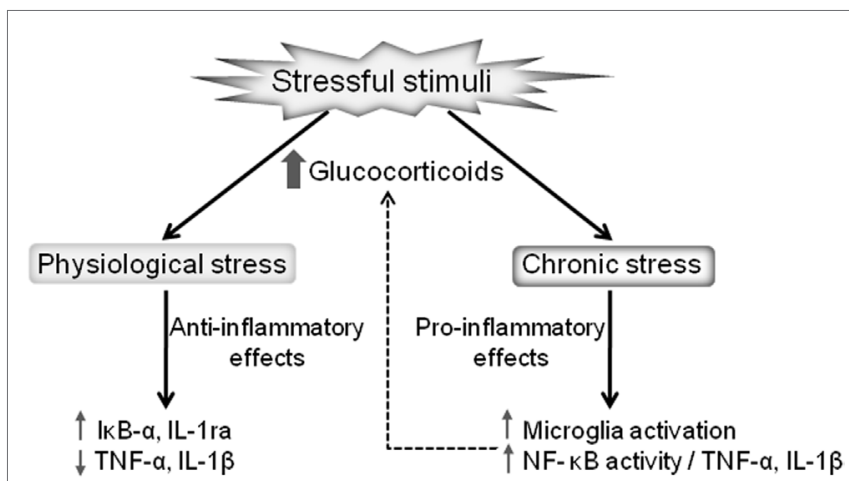

FIGURE 1 | Dual effects of stressful stimuli on glucocorticoidmediated regulation of inflammation. Glucocorticoids released after a mild stressor results in anti-inflammatory actions, reducing the proinflammatory cytokines production and increasing the expression of anti-inflammatory proteins, such as IL-1ra and $\mathrm{I}_{\mathrm{K} B}-\alpha$. On the other hand, pathological stressful stimuli lead to chronically elevated glucocorticoids promoting proinflammatory actions, including microglia activation and the consequent upregulation of the NF-кB proinflammatory cascade. 
to beneficial inflammatory processes, supporting the tissue in coping with stressors (74), the maintenance of a chronic inflammatory status is associated with the development of many pathologies, including neurodegenerative disorders such as Alzheimer's disease. These studies point out to the importance of estrogens as regulators of microglial activity, thus highlighting the potential of this mechanism as a way to modulate dysregulated inflammation.

Estradiol also has anti-inflammatory effects in astrocytes. Treatment with either estradiol or ER modulators inhibits astrocyte proliferation to a plethora of insults, such as stab wound injury $(75,76)$, kainic acid ablation (77), and in a MPTP model of Parkinson's disease (78). Additionally, estradiol also inhibits amyloid $\beta(\mathrm{A} \beta)$-induced elevation in IL- $1 \beta$ and TNF- $\alpha$ levels, as well as COX-2 and iNOS expression, in primary cultured astrocytes (79). Estradiol treatment also attenuates the increased hippocampal expression of IL- $1 \beta$ and TNF- $\alpha$, as well as astrocyte activation, in OVX rats, which is mediated via decreased NF- $\kappa \mathrm{B}$ signaling (80). Moreover, a reduction in proinflammatory cytokine and chemokine mRNA content is observed in cultured astrocytes that have been prior-treated with estradiol and ER modulators before LPS stimulation (81).

Indeed, ER modulators seem to have anti-inflammatory effects, as proven in several in vivo and in vitro experimental models. Such data indicate that ER- $\alpha$ deletion, specifically in astrocytes (but not neurons), lowers the beneficial effects of an ER- $\alpha$ ligand treatment, in an experimental autoimmune encephalomyelitis (EAE) animal model, as seen by clinical function, central inflammation, and axonal loss on female mice (82). Additionally, astroglial cell death and mitochondrial function are rescued by an estradiol pretreatment in an in vitro oxygen/glucose deprivation model (83).

Likewise, in vitro astrocyte cultures have a diminished inflammatory response following ER manipulations, as seen by an ER- $\beta$-dependent reduction in NF- $\kappa \mathrm{B}$ signaling (84), reduction in COX and iNOS expression (79), and overall reduction in proinflammatory cytokine release (84). In addition, estrogen has a positive effect on astrocytic glutamate re-uptake, by increasing glutamate transporters GLT-1 and GLAST (85), contributing to the functioning of glutamatergic synapses, as well as affording neuroprotection against the excitotoxic effects of raised levels of extracellular glutamate.

Many other in vivo models of inflammation also indicate estrogen to be neuroprotective. Estradiol reduces brain levels of TNF- $\alpha$, IL- $1 \beta$, and IL- 6 in male rats in model of severe peripheral burning injury (34). Additionally, low doses of progesterone or high doses of estrogen attenuate the raised levels of IL-1 $\beta$ that are evident $24 \mathrm{~h}$ after a traumatic brain injury in female rats, although the sex hormones increased the cytokine levels in the early inflammatory phase (86). Interestingly, Zhang et al. (87) suggested that not only circulating but also brain-derived estrogen might act as anti-inflammatory modulator. They showed, in a model of global cerebral ischemia in female rats, that hippocampal astrocyte activation was associated with an increase in aromatase expression, with consequent elevations of estradiol levels in the CA1 region, while suppression of its expression through antisense oligonucleotides enhanced cell death as well as astrocyte and microglial activation (87).
Nonetheless, not all studies indicate beneficial effects of estrogens. Chronic estrogen treatment of OVX rats impairs their performance in a water maze test in a way that is similar to that of LPS. When both estrogen treatment and LPS were combined, performance was further decreased (88). Interestingly, although exerting an anti-inflammatory effect in young females, estradiol increases brain IL-1 $\beta$ levels in reproductively senescent rats (89), thus highlighting that aging might impair the protective response to estrogens. Accordingly, in a model of systemic lupus erythematosus in female mice, genetic deficiency of ER- $\alpha$ decreased Iba $1^{+}$-activated microglia and rescued the cognitive deficit as assessed by the radial arm water maze test (90).

Overall, most studies suggest a protective effect of both testosterone and estrogens, although many factors may act to complicate such general conclusions, on occasion inverting these beneficial effects, which highlights the importance of further assessing the biological underpinnings that drive such complications. It is possible that the further assessment of testosterone/ estrogen ratio - instead of single hormone level analyses - could help to further elucidate the reason for such paradoxical results, since it seems to have a greater physiological relevance (30). In addition, the complex effects of estrogens in inflammation might also be dependent on distinct activation of specific ER subtypes, ER- $\alpha$ and ER- $\beta(84,91,92)$, and may also vary between different models.

\section{INVOLVEMENT OF STEROID HORMONES IN DIETARY INTERVENTIONS}

\section{HFD and Glucocorticoids}

Behavioral impacts of chronic exposure to a HFD can last for months, and their progression develops differently depending on which stage of the lifespan HFD exposure occurs. For example, rats chronically exposed to a lipid overload in their pre- and postnatal period exhibit anxiety-like behavior when adults, as measured by open field and elevated plus maze tasks $(93,94)$. HFD consumption during pregnancy impairs maternal behavior in mice, increasing circulating levels of corticosterone. Although the fetus is usually protected against maternal glucocorticoids due to placenta expression of 11beta-hydroxysteroid dehydrogenase type 2 (11 $\beta$-HSD2), mice fed with a HFD have a lower expression of placental $11 \beta-H S D 2$, rendering the fetus vulnerable to the effects of maternal circulating levels of glucocorticoids (95). Alterations in the gene expression of GRs in the amygdala as well as pro- and anti-inflammatory gene expression profiles in the amygdala and hippocampus of the offspring as adults could explain the increased anxiety-like behavior of animals exposed to HFD in pre- and perinatal periods of their early development $(94,96)$.

High-fat diet consumption by adult rats also alters their HPA axis response to stress, resulting in elevated glucocorticoid levels (97). Such altered response may be due to an increased noradrenergic input in the paraventricular nucleus (PVN) of the hypothalamus, an area responsible for controlling corticotrophinreleasing hormone $(\mathrm{CRH})$ delivery to the pituitary. Indeed, HFD induces tyrosine hydroxylase expression in the PVN area and 
increases CRH levels in the median eminence, part of the hypophyseal portal system (98). Besides HPA axis regulation, HFD in adults has a clear impact on systemic and central inflammation, dysregulating inflammatory gene expression, which, among other disorders, plays a central role in the development of insulin resistance $(99,100)$.

Disruption of some components of corticosteroid signaling has also been reported in several rat brain regions following chronic HFD consumption. Regulation of mineralocorticoid receptors and GRs, respectively, seems to be region-specific, increasing in some brain areas and diminishing in others. After chronic exposure to HFD, hippocampi of female rats exhibit a lower expression of both corticosteroid receptors (101), while an increase in amygdala levels of MR and GR was observed (94). However, both of these alterations can have similar stress-regulatory effects, with amygdala GR activation enhancing the stress response, while a loss of the HPA axis suppressive effects of the hippocampal GR by HFD, leading to a loss of its inhibition of the stress response (102). As well as such hippocampal changes arising from chronic stress, they are also evident in wider neurodegenerative-associated processes, including aging $(103,104)$. In all these cases, reduced expression of hippocampal corticosteroid receptors is associated with an exaggerated response to stress, confirming the inhibitory effect of hippocampal projections on the HPA axis.

It is well known that NF- $\kappa \mathrm{B}$ activity is affected by GR expression and signaling (35). Corticosterone, through GR activation, can induce apoptosis in lymphocytes (105), which explains the first observed data linking stress to immunosuppressant effects. Chronic supraphysiological levels of glucocorticoids are able to hinder immunity responses, reducing leukocyte count and impairing expression of several proinflammatory cytokines (106). Acting as an immunosuppressant, glucocorticoids have direct antagonizing effects upon NF- $\mathrm{KB}$ signaling, enhancing the expression of $\mathrm{I} \kappa \mathrm{B}$ and promoting the interaction between the GR and NF- $\mathrm{BB}$ in the nucleus, which, among many other effects, can decrease immune activation (106). On the other hand, increased immune response is also reported in initial phases of a stressful stimulus, an effect that is dependent upon basal levels of corticosterone (107). Given such a collection of data, it is not surprising that HFD can alter NF- $\mathrm{\kappa B}$ activity and the expression of different inflammatory cytokines. In mouse peripheral tissues, the expression of NF- $\kappa \mathrm{B}$ is increased in response to a chronic HFD. Enhanced NF- $\kappa B$ expression and activity was also reported in the amygdala of rats exposed to a HFD in their perinatal period (94), while diminished NF- $\kappa B$ expression is found in their hippocampus (101). Corroborating the central protective role of NF- $\mathrm{B}$, especially in the hippocampus, recent data show that a HFD can impair hippocampal neurogenesis, while elevating plasma corticosterone levels (108). Several other studies indicate different deleterious effects caused by a HFD upon hippocampal neuron functioning, including diminished BDNF production, impaired neuronal plasticity $(109,110)$, and working memory deficits (111). Interestingly, impaired hippocampal neurogenesis in HFD rodents does not correlate with fat accumulation but rather to serum corticosterone levels (108). In fact, high serum corticosterone levels affect proliferation, differentiation, and apoptosis in the dentate gyrus of rodents in different experimental settings $(112,113)$, indicating the significant role that alterations in the HPA axis play in HFD models.

The correlation between obesity and cognitive impairment has been extensively described in the past decade and several potential mechanisms were proposed trying to explain this link. Of these hypotheses, a few stand out. Impaired insulin and leptin signaling $(114,115)$ in the hippocampus and other memory-related brain regions is emerging as an interesting theory that forces us to further investigate the role of these two hormones in the physiology of the brain and specifically their purpose regarding synaptic function. However, considering the inflammatory pattern associated with obesity, it is not surprising that a large body of evidence supports the idea of a neuroinflammatory trigger to the cognitive deterioration associated with a HFD and obesity.

In this context, local proinflammatory cytokine production has been reported to occur in some brain regions after different HFD protocols (116-118). In all these cases, anti-inflammatory and/or antioxidant treatment (both pharmacological and nonpharmacological interventions) were able to revert HFD-induced cognitive impairment. This cognitive improvement seems to be accompanied not only by a reduction in inflammatory and oxidative stress markers but also with a reduced neuronal insulin resistance, driving a strong correlation between these factors.

Reinforcing the important role of neuroinflammation, several studies have also described an increase in blood-brain barrier (BBB) permeability caused by a HFD, in turn leaving the CNS more vulnerable to the inflammatory signals produced in peripheral tissues. Such increases in BBB permeability are associated with cognitive decrements (119-121). Interestingly, a few reports suggest that this HFD-induced BBB defect may lead not only to cognitive impairment but could also be the connection between Western diet consumption and Alzheimer's disease $(122,123)$.

\section{HFD and Sex Hormones}

The effects of dietary lipids upon sex hormones have been the focus of many studies since the early 1990s, particularly with regard to female sex hormones. Such interest in female hormones was triggered by data showing blood and urine estrogen levels to correlate positively with breast cancer risk in postmenopausal women (124). Coupled to the role of estrogens in the regulation of Alzheimer's disease, manipulating estrogen levels has been extensively investigated, including how this can be achieved via dietary manipulations.

There is now a general consensus that a low-fat diet significantly reduces estrogen levels in healthy postmenopausal women $(125,126)$. Dietary effects on serum estradiol levels were assessed in a study comparing estradiol levels from Caucasian and Asian women (127). Postmenopausal Asian women consumed a total of $19 \%$ of their calories from lipids, whereas in Caucasian women, this percentage was $38 \%$. Serum estradiol levels were significantly lower in Asian women, being 30-70\% lower than postmenopausal Caucasian women. Dietary intervention studies in women to assess dietary lipid impact on estradiol levels usually apply a low-lipid diet, with only $10-25 \%$ of calories being lipid derived. Results from such studies show significant changes occurring as early as 3 months after the intervention, with the general serum estradiol reduction being around 13\% (126, 128-130). 
The consumption of omega-3 fatty acids is another possible dietary intervention that can modulate estradiol levels. Dietary omega-3 and omega-6 PUFA are both required in order to optimize health but can have differential effects on the inflammatory response. Omega-6 PUFA consumption increases the levels of a number of proinflammatory mediators, including prostaglandin E2 (PGE2) and leukotriene B4 (LB4), while omega-3 raises the levels of mediators with relatively lower inflammatory activity, such as prostaglandin E3 (PGE3) and leukotriene B5 (LB5). Both PGE2 and PGE3 and LB4 and LB5 are produced by the same enzymes, cyclooxygenase and 5-lipoxygenase, respectively. By enhancing substrate competition, omega-3 supplementation can reduce PGE2 and LB4 production, thereby attenuating the inflammatory response $(131,132)$. Furthermore, PGE2 can induce aromatase expression, thereby increasing the conversion of androgens to estrogens (133). This is an important mechanism that allows omega-3 PUFA consumption to inhibit estrogen production. Just as a low-lipid diet can decrease estradiol levels, a HFD can have the opposite effect. Young et al. (134) have shown a $36.6 \%$ increase in the plasma estradiol levels of postmenopausal women after 8 weeks of HFD, compared to that at baseline. However, this study was not able to show the influence of a lowfat, high omega-3 PUFA diet on estradiol levels.

While estradiol can have detrimental effects on peripheral tissues in postmenopausal women, including increasing breast cancer risk, studies in the CNS have shown some opposite effects. The protective role that sex hormones perform in the brain is well established, including from the use of several different experimental models, ranging from stroke to neurodegenerative disorders (135). Although the neuroprotective role of estrogen hormones is widely acknowledged, arising in part from data showing estrogens to increase anti-inflammatory mediators and protect against excitotoxicity, its use as a therapeutic agent is limited due to its activity in peripheral tissues, where it can lead to feminization and altered gonadal function as well as correlating positively with increased cancer risk, predominantly breast and endometrial cancers. Consequently, research has focused on the utility of using selective ER modulators. Tissue- and cell-specific ER modulators are a promising alternative, should they combine the desired pharmacological effect with little to no side effects.

Although not within the scope of this review, a HFD has opposite effects with regard to male sex hormone levels. Mice submitted to a HFD regimen of a duration of 10 weeks showed higher serum estradiol levels, as expected, but lower concentrations of both luteinizing, and consequently, testosterone hormones (136). Interestingly enough, metformin treatment of obese mice induced by HFD is capable of partially reverse obesity-induced elevated estradiol serum levels and decreased serum testosterone, while rescuing several fertility parameters (137).

\section{DER and Glucocorticoids}

Dietary energy restriction can be psychologically stressful. Being characterized by food deprivation and starvation, it can be coupled to negative emotions, such as anxiety, depression, and irritability (138). As a stressful stimulus, DER can increase HPA axis activity in a variety of species, thereby increasing an important stress indicator, namely, circulating glucocorticoid hormone levels. Furthermore, the glucocorticoid increase during DER would be expected to modulate metabolic functions, including by enabling nutrient mobilization that may be further catabolized for energy, such as the stimulation of gluconeogenesis, protein catabolism, which increases the release of constituent amino acids, and lipolysis, which sensitizes adipose tissue stored as triglyceride to the action of lipolytic substances (growth hormone and catecholamines), resulting in glycerol and fatty acids (139).

The theory of hormesis, whereby mild stressors can be beneficial, may help to explain the DER mechanisms (140). Unlike other chronic stressful stimuli, DER can have many favorable effects for the organism, including counteracting inflammation, extending life span, and reducing the prevalence of age-related diseases. It is theorized that the DER potentiation of glucocorticoids release may contribute to increased stress resistance, protecting the organism not only against the stressor itself but also by upregulating adaptive pathways that protect the organism against the exacerbation of inflammation, infection, and metabolic disorders that can disturb homeostasis (141-144). Noteworthy, Dhurandhar et al. (145) recently proposed that the DER protective mechanisms may involve stress-related interceptive cues, as hunger in the absence of dietary restriction, as induced by a ghrelin agonist, promotes the same beneficial effects as DER, counteracting inflammation, aging, and neurodegeneration.

Among the mechanisms by which DER effects occur, neuroendocrinological alterations may play an important role (146). As previously noted, increased glucocorticoid concentrations following DER occur in various species. For instance, glucocorticoids are moderately increased by DER in rodents, where it is suggested to play a role in the DER effect (146-150). Free corticosterone levels are increased in rats after DER at any point in lifespan, when compared to age-matched ad libitum (151). This has led to the proposal that a lifetime DER-induced daily hyperadrenocorticism may retard aging (152). Levay et al. (24) tested different DER doses of calorie restriction (CR) in rats ranging from 12.5 to $50 \%$ and showed that all the doses caused an increase in corticosterone levels following a dose-response trend, with increasing restriction associated with higher glucocorticoid levels (24). Interestingly, a study that evaluated whether DER would similarly affect cortisol concentrations in wild mice not subjected to many generations of laboratory selection similarly showed that DER elevates corticosterone levels throughout life, suggesting that this DER effect is not altered by genetic breeding effects (153).

In humans, DER has been shown to increase perceived stress and circulating cortisol concentrations (154). Moreover, athletes have higher cortisol secretion following DER (155), as do individuals with anorexia nervosa (156). The study of eight participants who were subjected to DER for 2 years in a closed ecological space (Biosphere 2) also showed increased morning total cortisol (157). Interestingly, Grayson et al. (158) reported that rodent weight loss induced by DER increased basal HPA axis activity, unlike the same level of weight loss induced by bariatric surgery. Cortisol is usually released in a circadian rhythm, being an important aspect of the circadian system. Higher circulating cortisol levels are observed during the early morning, with lower levels evident around midnight. Remarkably, the elevated glucocorticoid levels 
after DER, which is accompanied by an oscillation in the levels of GRs, follow an altered circadian profile $(147,159)$. Another study, using 40\% CR mice, in comparison to ad libitum fed controls, showed a 10-fold increase of plasma corticosteroid levels at 7:00 a.m., a 2-fold increase at 4:00 p.m., and no difference at 11:00 p.m. in the circadian cycle (160).

During Ramadan, adult Muslims refrain from eating during daytime. Ramadan can be considered a DER, in which the frequency of food consumption is restricted [intermittent fasting (IF)] but not the levels of calories consumed. Literature data suggest that Ramadan decreases the amplitude of the cortisol circadian rhythm by increasing its nocturnal levels while decreasing its diurnal circulating levels (161-163). A serum cortisol increase at 3:00 p.m. can occur in Ramadan (164). During Ramadan, although still within the normal reference ranges, immune cells can also significantly decrease, as well as proinflammatory cytokines and chemokines levels, with consequences, e.g., cancerassociated processes $(165,166)$.

However, although it has commonly been shown that DER increases cortisol levels in primates and rodents, there is also evidence to suggest otherwise. It seems that cortisol modulation by DER varies depending on the species, protocol, and other circumstances studied. For instance, it has recently been shown that a mild 25\% CR diet does not alter the salivary cortisol levels of overweight men and women (167). In another study with obese individuals submitted to mild CR for 3 weeks, although reduced cortisol production and the metabolism of cortisol and cortisone were observed, there was no alteration on plasma cortisol levels. Conversely, in the same study, obese individuals starved for 6 days showed increased plasma cortisol levels (168). Also, Sticker et al. (169) showed that 50\% CR in horses led to decreased plasma cortisol levels, compared to controls. Accordingly, Glade et al. (170) showed that during prolonged DER, young horses on an $80 \%$ CR also showed decreased cortisol levels, when compared with horses fed with meals containing $160 \%$ of their energy requirements.

Importantly, not in all glucocorticoid-sensitive cell types may derive stress inoculation benefits from DER-induced cortisol release. For instance, previous studies suggest that glucocorticoids can render hippocampal and cortical neurons more vulnerable to metabolic, excitotoxic, and oxidative damage (171). Although it was previously demonstrated that DER upregulates brain heat shock proteins $(172,173)$, GR activation can downregulate the expression of several genes, including heat shock protein 70 , known to be important to counteract stress-induced cell damage (174). DER in rodents leads to glucocorticoid release that can reduce neuronal sensitivity to glucocorticoids by promoting a feedback suppression on the levels of the potentially damaging GR, thereby increasing the resistance to injury (175).

A large body of evidence strengthens the proposed link between glucocorticoids and the anti-inflammatory effects of DER in rodents. Besides its metabolic actions, glucocorticoids are also known for their anti-inflammatory activities due to the inhibition of key inflammatory transcriptional regulators, such as the activator protein-1 (AP-1) and NF- $\mathrm{B}$, known to activate the transcription of proinflammatory cytokines (39).
Dietary energy restriction has also been linked to protection against inflammation. Vasconcelos et al. (176) showed that the IF protocol prevents or mitigates cognitive deficits, inflammatory genes transcription, and the diverse array of systemic LPS-induced cytokines in the brain and the periphery. Furthermore, 50\% CR also reduces sickness behavior, fever, and peripheral immune markers following LPS injection, which was also modulated by DER duration $(177,178)$. In this DER protocol, elevated circulating corticosterone levels were evident, which the authors suggest contributes to the diminished proinflammatory signals in these animals (178). In another study, 40\% CR in mice also prevented the LPS-induced proinflammatory cytokines upregulation, which was again accompanied by increased glucocorticoid production (179). Supporting this theory, previous data reported that adrenalectomized mice are much more sensitive to the lethal effect of LPS, which is prevented by the pretreatment with dexamethasone $(33,49)$. Such data highlight the immune-regulatory effects of glucocorticoids, including in CR paradigms.

Inflammation has long been associated with the development of cancer, which partly explains the association of obesity and tumorigenesis. By contrast, DER powerfully inhibits the development of cancer in many studies (180), including in wild mice as well as laboratory-reared rodents, indicating that laboratory selection does not interfere in this effect (153). Both topical and oral glucocorticoid treatments decrease tumor development in rodents (181-185). Adrenalectomy reverses the inhibition of tumorigenesis by DER in mice and glucocorticoids supplementation restores it, suggesting that adrenal hormones play an important role in mediating this DER effect (186-188).

An extensive literature shows inflammation to be a risk factor for cognitive impairment and dementia, with neuroinflammatory processes contributing to neurodegeneration $(189,190)$. Most neurodegenerative conditions are associated with chronic inflammation, which is widely accepted as contributing to the pathophysiology of neurodegenerative conditions (191-193). DER can prevent or attenuate inflammation associated with neurodegeneration (194-196). Studies also suggest that glucocorticoids play an important role, with some differential effects that are dependent on whether they are applied acutely or chronically, in neurodegeneration, such as in Alzheimer's disease, being associated with chronic glucocorticoids (197-199), while acute conditions, such as ischemic stroke, benefiting from the acute effects of glucocorticoids (171). Such effects are relevant both clinically and in animal models.

Despite the DER-induced increase in glucocorticoids classically known for their anti-inflammatory action, studies have shown mixed results when evaluating the immune response to infection and pathogen clearance efficiency in animals submitted to DER protocols. In primates and rodent studies, while DER can improve clearance and survival after bacterial infection and enhance interferon gamma (IFN- $\gamma$ ) production, it can promote a deficient innate immune response with reduced ability to control infections by monocytes and macrophages (200-204). Patel and Finch (205) suggest that DER-induced glucocorticoid release may promote a differential effect on immunity in different parts of the organism, for instance, activating pathways close to the infectious 
focus that are not suppressed by glucocorticoids and attenuating inflammation at other locations.

A brief summary of DER and HFD modulatory effects on neuroinflammation through glucocorticoid signaling is outlined in Figure 2.

\section{DER and Sex Hormones}

Numerous studies have demonstrated that DER protocols affect sex hormone levels. In rhesus monkeys, for instance, 30\% CR deferred the age-related dehydroepiandrosterone decline in males (28). Accordingly, Levay et al. (24) observed a dose-response decrease in testosterone levels in male rats with increasing CR severity. This effect was also observed for the IF protocol (32). A severe CR protocol in men also decreased levels of testosterone and estradiol while increasing levels of SHBG (31). In women, IF also increases SHBG levels, although CR more significantly reduces dehydroepiandrosterone levels (206). In the Biosphere 2 study, Walford et al. (157) observed an increase in levels of androstenedione and SHBG in humans (both in male and female participants), while the levels of estradiol, but not testosterone, decreased in men.

In contrast to these results, Martin et al. (29) observed that male rats submitted to IF or females under $40 \%$ CR had increased levels of testosterone. In a subsequent study, they observed that either a $40 \%$ CR or an IF protocol increased the testosterone/ estrogen ratio, consistent with a hyper-masculinization state. A similar effect was also observed in females under the $40 \%$ CR protocol (30). Furthermore, Kumar and Kaur (32) showed that IF induced a significant decrease in luteinizing hormone, associated with diminished levels of estradiol in female rats, which completely suppressed the estrous cycle. Other studies also showed DER to inhibit estradiol levels $(29,30)$.

In conclusion, the effects of both DER interventions on sex hormones levels - including the testosterone/estrogen ratio - as well as the relevance of this modulation on DER anti-inflammatory properties are still obscure and have yet to be clarified. The interrelationship between sex hormones and neuroinflammation, as discussed above, is summarized in Figure 3.

\section{CONCLUDING REMARKS}

In conclusion, glucocorticoids have been historically characterized as mediators of many anti-inflammatory effects observed within DER protocols, closely implicating glucocorticoid pathways in DER, including in the development of future pharmacological interventions that could mimic DER benefits. In contrast, extensive data support the hypothesis that the detrimental effects of a HFD upon cognitive function and behavior are caused by enhanced glucocorticoid signaling accompanied by neuroinflammation. As such, it is clear that there is more to glucocorticoid effects than simply its serum levels. Although both DER and HFD contribute to enhanced glucocorticoid blood concentration, its effects are quite opposite regarding health and, specifically, inflammation. Also, DER may induce its positive effects through other different mechanisms not related to glucocorticoid signaling, as may be the case for the detrimental effects of a HFD.

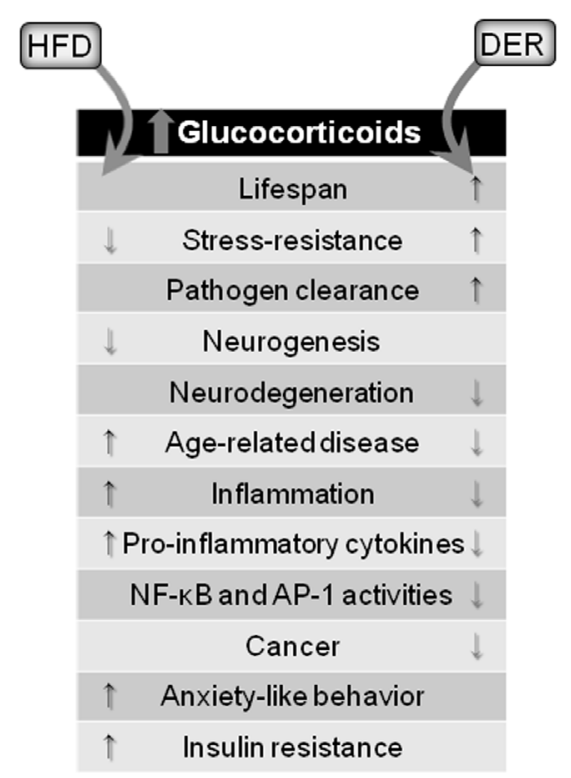

FIGURE 2 | Glucocorticoid-mediated effects of dietary interventions. Both HFD and DER results in increased blood concentrations of glucocorticoids. However, opposing effects are observed. HFD, via glucocorticoids release, cause detrimental effects to the brain and organism, while DER-induced glucocorticoids release leads to protective effects.

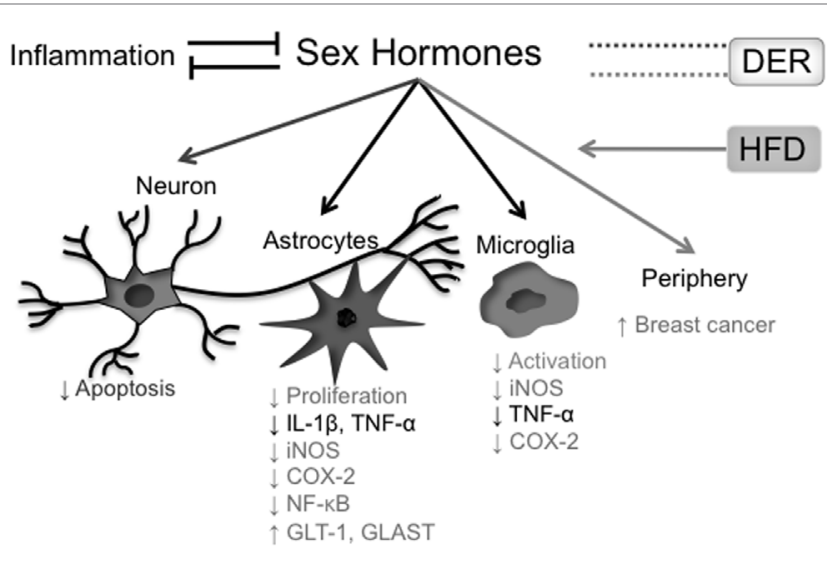

FIGURE 3 | Effects of sex hormones on the inflammatory process. Presence of systemic inflammatory markers correlates inversely with blood concentrations of sex hormones, while hormonal reposition reduces both central and peripheral cytokine production. In the CNS, testosterone has protective roles both in neurons and glial cells, where it shows an antiinflammatory action. Estradiol also has anti-inflammatory properties in glial cells (astrocytes and microglia). On the other hand, estradiol levels in postmenopausal women positively correlate with breast cancer incidence. A HFD raises estradiol blood levels in postmenopausal women, increasing breast cancer risk. The effects of different DER protocols on sex hormone levels are more controversial. In black, effects of and on both testosterone and estradiol; in light gray, effects related to estradiol; in dark gray, effects related to testosterone. 
Given that androgen and estrogen levels also appear to be variably modulated by DER interventions and overall dietary lipid load, which is at least partly dependent on sex, age, and inflammatory status, it is possible that these hormones could have a relevant role to play in DER anti-inflammatory mechanisms and HFD-induced inflammation. However, this effect is still unclear. It is therefore important that future research should better clarify the role that such sex hormones play in DER and HFD mechanisms.

\section{AUTHOR CONTRIBUTIONS}

All the authors contributed to the design of the paper, literature review, writing of the manuscript, and creation of the figures.

\section{REFERENCES}

1. Mitchell S, Shaw D. The worldwide epidemic of female obesity. Best Pract Res Clin Obstet Gynaecol (2015) 29(3):289-99. doi:10.1016/j. bpobgyn.2014.10.002

2. Ogden CL, Carroll MD, Kit BK, Flegal KM. Prevalence of childhood and adult obesity in the United States, 2011-2012. JAMA (2014) 311(8):806-14. doi:10.1001/jama.2014.732

3. Gregor MF, Hotamisligil GS. Inflammatory mechanisms in obesity. Annu Rev Immunol (2011) 29:415-45. doi:10.1146/annurev-immunol-031210-101322

4. Caro JF, Sinha MK, Kolaczynski JW, Zhang PL, Considine RV. Leptin: the tale of an obesity gene. Diabetes (1996) 45(11):1455-62. doi:10.2337/ diab.45.11.1455

5. Maffei M, Halaas J, Ravussin E, Pratley RE, Lee GH, Zhang Y, et al. Leptin levels in human and rodent: measurement of plasma leptin and ob RNA in obese and weight-reduced subjects. Nat Med (1995) 1(11):1155-61. doi:10.1038/nm1195-1155

6. Herrmann TS, Bean ML, Black TM, Wang P, Coleman RA. High glycemic index carbohydrate diet alters the diurnal rhythm of leptin but not insulin concentrations. Exp Biol Med (Maywood) (2001) 226(11):1037-44.

7. Lopes IM, Forga L, Martinez JA. Effects of leptin resistance on acute fuel metabolism after a high carbohydrate load in lean and overweight young men. J Am Coll Nutr (2001) 20(6):643-8. doi:10.1080/07315724.2001.1071 9162

8. Weigle DS, Cummings DE, Newby PD, Breen PA, Frayo RS, Matthys CC, et al. Roles of leptin and ghrelin in the loss of body weight caused by a low fat, high carbohydrate diet. J Clin Endocrinol Metab (2003) 88(4):1577-86. doi:10.1210/jc.2002-021262

9. Kong A, Neuhouser ML, Xiao L, Ulrich CM, McTiernan A, Foster-Schubert KE. Higher habitual intake of dietary fat and carbohydrates are associated with lower leptin and higher ghrelin concentrations in overweight and obese postmenopausal women with elevated insulin levels. Nutr Res (2009) 29(11):768-76. doi:10.1016/j.nutres.2009.10.013

10. Martin LJ, Siliart B, Lutz TA, Biourge V, Nguyen P, Dumon HJ. Postprandial response of plasma insulin, amylin and acylated ghrelin to various test meals in lean and obese cats. Br J Nutr (2010) 103(11):1610-9. doi:10.1017/ S000711450999359X

11. Roberts CK, Berger JJ, Barnard RJ. Long-term effects of diet on leptin, energy intake, and activity in a model of diet-induced obesity. J Appl Physiol (1985) (2002) 93(3):887-93. doi:10.1152/japplphysiol.00224.2002

12. Hynes GR, Heshka J, Chadee K, Jones PJ. Effects of dietary fat type and energy restriction on adipose tissue fatty acid composition and leptin production in rats. J Lipid Res (2003) 44(5):893-901. doi:10.1194/jlr.M200318-JLR200

13. Higuchi T, Shirai N, Saito M, Suzuki H, Kagawa Y. Levels of plasma insulin, leptin and adiponectin, and activities of key enzymes in carbohydrate metabolism in skeletal muscle and liver in fasted ICR mice fed dietary n-3 polyunsaturated fatty acids. J Nutr Biochem (2008) 19(9):577-86. doi:10.1016/j. jnutbio.2007.08.001

14. Hill JO, Peters JC. Environmental contributions to the obesity epidemic. Science (1998) 280(5368):1371-4. doi:10.1126/science.280.5368.1371

\section{ACKNOWLEDGMENTS}

The authors would like to thank George Anderson of CRC Scotland and London for English editing services.

\section{FUNDING}

This publication was supported by grants from Fundação de Amparo à Pesquisa do Estado de São Paulo (FAPESP), Conselho Nacional de Desenvolvimento Científico e Tecnológico (CNPq), and University of São Paulo (USP). AV and CM are supported by Ph.D. fellowships from FAPESP and JC-C by an M.Sc. fellowship from FAPESP. EK and CS are research fellows from FAPESP and $\mathrm{CNPq}$, respectively.

15. Flegal KM, Graubard BI, Williamson DF, Gail MH. Excess deaths associated with underweight, overweight, and obesity. JAMA (2005) 293(15):1861-7. doi:10.1001/jama.293.15.1861

16. Kahn SE, Hull RL, Utzschneider KM. Mechanisms linking obesity to insulin resistance and type 2 diabetes. Nature (2006) 444(7121):840-6. doi:10.1038/ nature 05482

17. Carpiniello B, Pinna F, Pillai G, Nonnoi V, Pisano E, Corrias S, et al. Obesity and psychopathology. A study of psychiatric comorbidity among patients attending a specialist obesity unit. Epidemiol Psichiatr Soc (2009) 18(2):119-27.

18. Lim U, Ernst T, Wilkens LR, Albright CL, Lum-Jones A, Seifried A, et al. Susceptibility variants for waist size in relation to abdominal, visceral, and hepatic adiposity in postmenopausal women. J Acad Nutr Diet (2012) 112(7):1048-55. doi:10.1016/j.jand.2012.03.034

19. Zhi T, Wang Q, Liu Z, Zhu Y, Wang Y, Shi R, et al. Body mass index, waist circumference and waist-hip ratio are associated with depressive symptoms in older Chinese women: results from the Rugao Longevity and Ageing Study (RuLAS). Aging Ment Health (2015) 21:1-6. doi:10.1080/13607863.2015.11 24837

20. Desai RA, Manley M, Desai MM, Potenza MN. Gender differences in the association between body mass index and psychopathology. CNS Spectr (2009) 14(7):372-83.

21. McCrea RL, Berger YG, King MB. Body mass index and common mental disorders: exploring the shape of the association and its moderation by age, gender and education. Int J Obes (Lond) (2012) 36(3):414-21. doi:10.1038/ ijo. 2011.65

22. Longo VD, Mattson MP. Fasting: molecular mechanisms and clinical applications. Cell Metab (2014) 19(2):181-92. doi:10.1016/j.cmet.2013.12.008

23. Garcia-Belenguer S, Oliver C, Mormede P. Facilitation and feedback in the hypothalamo-pituitary-adrenal axis during food restriction in rats. $J$ Neuroendocrinol (1993) 5(6):663-8. doi:10.1111/j.1365-2826.1993.tb00537.x

24. Levay EA, Tammer AH, Penman J, Kent S, Paolini AG. Calorie restriction at increasing levels leads to augmented concentrations of corticosterone and decreasing concentrations of testosterone in rats. Nutr Res (2010) 30(5):366-73. doi:10.1016/j.nutres.2010.05.001

25. McDowell GH. Hormonal control of glucose homoeostasis in ruminants. Proc Nutr Soc (1983) 42(2):149-67. doi:10.1079/PNS19830021

26. Wilckens T, De Rijk R. Glucocorticoids and immune function: unknown dimensions and new frontiers. Immunol Today (1997) 18(9):418-24. doi:10.1016/S0167-5699(97)01111-0

27. KellyJJ,Mangos G, Williamson PM, Whitworth JA. Cortisol and hypertension. Clin Exp Pharmacol Physiol (1998) 25:S51-6. doi:10.1111/j.1440-1681.1998. tb02301.x

28. Mattison JA, Lane MA, Roth GS, Ingram DK. Calorie restriction in rhesus monkeys. Exp Gerontol (2003) 38(1-2):35-46. doi:10.1016/ S0531-5565(02)00146-8

29. Martin B, Pearson M, Kebejian L, Golden E, Keselman A, Bender M, et al. Sex-dependent metabolic, neuroendocrine, and cognitive responses to dietary energy restriction and excess. Endocrinology (2007) 148(9):4318-33. doi:10.1210/en.2007-0161 
30. Martin B, Pearson M, Brenneman R, Golden E, Wood W, Prabhu V, et al. Gonadal transcriptome alterations in response to dietary energy intake: sensing the reproductive environment. PLoS One (2009) 4(1):e4146. doi:10.1371/ journal.pone.0004146

31. Cangemi R, Friedmann AJ, Holloszy JO, Fontana L. Long-term effects of calorie restriction on serum sex-hormone concentrations in men. Aging Cell (2010) 9(2):236-42. doi:10.1111/j.1474-9726.2010.00553.x

32. Kumar S, Kaur G. Intermittent fasting dietary restriction regimen negatively influences reproduction in young rats: a study of hypothalamo-hypophysial-gonadal axis. PLoS One (2013) 8(1):e52416. doi:10.1371/journal. pone.0052416

33. Parant M, Le Contel C, Parant F, Chedid L. Influence of endogenous glucocorticoid on endotoxin-induced production of circulating TNF-alpha. Lymphokine Cytokine Res (1991) 10(4):265-71.

34. Gatson JW, Maass DL, Simpkins JW, Idris AH, Minei JP, Wigginton JG. Estrogen treatment following severe burn injury reduces brain inflammation and apoptotic signaling. J Neuroinflammation (2009) 6:30. doi:10.1186/1742-2094-6-30

35. Sorrells SF, Caso JR, Munhoz CD, Sapolsky RM. The stressed CNS: when glucocorticoids aggravate inflammation. Neuron (2009) 64(1):33-9. doi:10.1016/j.neuron.2009.09.032

36. Brand JS, van der Schouw YT, Dowsett M, Folkerd E, Luben RN, Wareham NJ, et al. Testosterone, SHBG and differential white blood cell count in middle-aged and older men. Maturitas (2012) 71(3):274-8. doi:10.1016/j. maturitas.2011.12.007

37. Bellavance MA, Rivest S. The HPA - immune axis and the immunomodulatory actions of glucocorticoids in the brain. Front Immunol (2014) 5:136. doi:10.3389/fimmu.2014.00136

38. Homo-Delarche F, Fitzpatrick F, Christeff N, Nunez EA, Bach JF, Dardenne M. Sex steroids, glucocorticoids, stress and autoimmunity. J Steroid Biochem Mol Biol (1991) 40(4-6):619-37. doi:10.1016/0960-0760(91)90285-D

39. De Bosscher K, Vanden Berghe W, Haegeman G. Mechanisms of anti-inflammatory action and of immunosuppression by glucocorticoids: negative interference of activated glucocorticoid receptor with transcription factors. J Neuroimmunol (2000) 109(1):16-22. doi:10.1016/S0165-5728(00)00297-6

40. Almawi WY, Melemedjian OK. Negative regulation of nuclear factor-kappaB activation and function by glucocorticoids. J Mol Endocrinol (2002) 28(2):69-78. doi:10.1677/jme.0.0280069

41. Franchimont D. Overview of the actions of glucocorticoids on the immune response: a good model to characterize new pathways of immunosuppression for new treatment strategies. Ann N Y Acad Sci (2004) 1024:124-37. doi:10.1196/annals.1321.009

42. Kadmiel M, Cidlowski JA. Glucocorticoid receptor signaling in health and disease. Trends Pharmacol Sci (2013) 34(9):518-30. doi:10.1016/j. tips.2013.07.003

43. Vandevyver S, Dejager L, Tuckermann J, Libert C. New insights into the anti-inflammatory mechanisms of glucocorticoids: an emerging role for glucocorticoid-receptor-mediated transactivation. Endocrinology (2013) 154(3):993-1007. doi:10.1210/en.2012-2045

44. Besedovsky HO, del Rey A, Klusman I, Furukawa H, Monge Arditi G, Kabiersch A. Cytokines as modulators of the hypothalamus-pituitary-adrenal axis. J Steroid Biochem Mol Biol (1991) 40(4-6):613-8. doi:10.1016/0960-0760(91)90284-C

45. Hansen MK, Nguyen KT, Fleshner M, Goehler LE, Gaykema RP, Maier SF, et al. Effects of vagotomy on serum endotoxin, cytokines, and corticosterone after intraperitoneal lipopolysaccharide. Am J Physiol Regul Integr Comp Physiol (2000) 278(2):R331-6.

46. Bertini R, Bianchi M, Ghezzi P. Adrenalectomy sensitizes mice to the lethal effects of interleukin 1 and tumor necrosis factor. J Exp Med (1988) 167(5):1708-12. doi:10.1084/jem.167.5.1708

47. MacPhee IA, Antoni FA, Mason DW. Spontaneous recovery of rats from experimental allergic encephalomyelitis is dependent on regulation of the immune system by endogenous adrenal corticosteroids. J Exp Med (1989) 169(2):431-45. doi:10.1084/jem.169.2.431

48. Edwards CK III, Yunger LM, Lorence RM, Dantzer R, Kelley KW. The pituitary gland is required for protection against lethal effects of Salmonella typhimurium. Proc Natl Acad Sci U S A (1991) 88(6):2274-7. doi:10.1073/ pnas.88.6.2274
49. Ramachandra RN, Sehon AH, Berczi I. Neuro-hormonal host defence in endotoxin shock. Brain Behav Immun (1992) 6(2):157-69. doi:10.1016/0889-1591(92)90015-G

50. Ruzek MC, Pearce BD, Miller AH, Biron CA. Endogenous glucocorticoids protect against cytokine-mediated lethality during viral infection. J Immunol (1999) 162(6):3527-33.

51. Nadeau S, Rivest S. Glucocorticoids play a fundamental role in protecting the brain during innate immune response. J Neurosci (2003) 23(13):5536-44.

52. de Pablos RM, Villaran RF, Arguelles S, Herrera AJ, Venero JL, Ayala A, et al. Stress increases vulnerability to inflammation in the rat prefrontal cortex. J Neurosci (2006) 26(21):5709-19. doi:10.1523/JNEUROSCI.0802-06.2006

53. Munhoz CD, Sorrells SF, Caso JR, Scavone C, Sapolsky RM. Glucocorticoids exacerbate lipopolysaccharide-induced signaling in the frontal cortex and hippocampus in a dose-dependent manner. J Neurosci (2010) 30(41):136908. doi:10.1523/JNEUROSCI.0303-09.2010

54. Sapolsky RM, Pulsinelli WA. Glucocorticoids potentiate ischemic injury to neurons: therapeutic implications. Science (1985) 229(4720):1397-400. doi:10.1126/science. 4035356

55. Dinkel K, MacPherson A, Sapolsky RM. Novel glucocorticoid effects on acute inflammation in the CNS. J Neurochem (2003) 84(4):705-16. doi:10.1046/j.1471-4159.2003.01604.x

56. Sorrells SF, Munhoz CD, Manley NC, Yen S, Sapolsky RM. Glucocorticoids increase excitotoxic injury and inflammation in the hippocampus of adult male rats. Neuroendocrinology (2014) 100(2-3):129-40. doi:10.1159/000367849

57. Munhoz CD, Lepsch LB, Kawamoto EM, Malta MB, Lima Lde S, Avellar MC, et al. Chronic unpredictable stress exacerbates lipopolysaccharide-induced activation of nuclear factor-kappaB in the frontal cortex and hippocampus via glucocorticoid secretion. J Neurosci (2006) 26(14):3813-20. doi:10.1523/ JNEUROSCI.4398-05.2006

58. Laaksonen DE, Niskanen L, Punnonen K, Nyyssonen K, Tuomainen TP, Salonen R, et al. Sex hormones, inflammation and the metabolic syndrome: a population-based study. Eur J Endocrinol (2003) 149(6):601-8. doi:10.1530/ eje.0.1490601

59. Kupelian V, Chiu GR, Araujo AB, Williams RE, Clark RV, McKinlay JB. Association of sex hormones and C-reactive protein levels in men. Clin Endocrinol(Oxf) (2010) 72(4):527-33. doi:10.1111/j.1365-2265.2009.03713.x

60. Haring R, Baumeister SE, Volzke H, Dorr M, Kocher T, Nauck M, et al. Prospective inverse associations of sex hormone concentrations in men with biomarkers of inflammation and oxidative stress. J Androl (2012) 33(5):944-50. doi:10.2164/jandrol.111.015065

61. Santos-Galindo M, Acaz-Fonseca E, Bellini MJ, Garcia-Segura LM. Sex differences in the inflammatory response of primary astrocytes to lipopolysaccharide. Biol Sex Differ (2011) 2:7. doi:10.1186/2042-6410-2-7

62. Jayaraman A, Lent-Schochet D, Pike CJ. Diet-induced obesity and low testosterone increase neuroinflammation and impair neural function. J Neuroinflammation (2014) 11:162. doi:10.1186/s12974-014-0162-y

63. Khosla S, Atkinson EJ, Dunstan CR, O'Fallon WM. Effect of estrogen versus testosterone on circulating osteoprotegerin and other cytokine levels in normal elderly men. J Clin Endocrinol Metab (2002) 87(4):1550-4. doi:10.1210/ jcem.87.4.8397

64. Rettew JA, Huet-Hudson YM, Marriott I. Testosterone reduces macrophage expression in the mouse of toll-like receptor 4, a trigger for inflammation and innate immunity. Biol Reprod (2008) 78(3):432-7. doi:10.1095/ biolreprod.107.063545

65. Hammond J, Le Q, Goodyer C, Gelfand M, Trifiro M, LeBlanc A. Testosterone-mediated neuroprotection through the androgen receptor in human primary neurons. J Neurochem (2001) 77(5):1319-26. doi:10.1046/j.1471-4159.2001.00345.x

66. Butchart J, Birch B, Bassily R, Wolfe L, Holmes C. Male sex hormones and systemic inflammation in Alzheimer disease. Alzheimer Dis Assoc Disord (2013) 27(2):153-6. doi:10.1097/WAD.0b013e318258cd63

67. Spence RD, Voskuhl RR. Neuroprotective effects of estrogens and androgens in CNS inflammation and neurodegeneration. Front Neuroendocrinol (2012) 33(1):105-15. doi:10.1016/j.yfrne.2011.12.001

68. Filgueira FP, Lobato NS, DosSantos RA, Oliveira MA, Akamine EH, Tostes $\mathrm{RC}$, et al. Endogenous testosterone increases leukocyte-endothelial cell interaction in spontaneously hypertensive rats. Life Sci (2012) 90(17-18):689-94. doi:10.1016/j.lfs.2012.03.009 
69. Vegeto E, Belcredito S, Ghisletti S, Meda C, Etteri S, Maggi A. The endogenous estrogen status regulates microglia reactivity in animal models of neuroinflammation. Endocrinology (2006) 147(5):2263-72. doi:10.1210/ en.2005-1330

70. Drew PD, Chavis JA. Female sex steroids: effects upon microglial cell activation. J Neuroimmunol (2000) 111(1-2):77-85. doi:10.1016/ S0165-5728(00)00386-6

71. Vegeto E, Bonincontro C, Pollio G, Sala A, Viappiani S, Nardi F, et al. Estrogen prevents the lipopolysaccharide-induced inflammatory response in microglia. J Neurosci (2001) 21(6):1809-18.

72. Tenenbaum M, Azab AN, Kaplanski J. Effects of estrogen against LPSinduced inflammation and toxicity in primary rat glial and neuronal cultures. J Endotoxin Res (2007) 13(3):158-66. doi:10.1177/0968051907080428

73. Baker AE, Brautigam VM, Watters JJ. Estrogen modulates microglial inflammatory mediator production via interactions with estrogen receptor beta. Endocrinology (2004) 145(11):5021-32. doi:10.1210/en.2004-0619

74. Loane DJ, Kumar A. Microglia in the TBI brain: the good, the bad, and the dysregulated. Exp Neurol (2016) 275(Pt 3):316-27. doi:10.1016/j. expneurol.2015.08.018

75. Garcia-Estrada J, Del Rio JA, Luquin S, Soriano E, Garcia-Segura LM. Gonadal hormones down-regulate reactive gliosis and astrocyte proliferation after a penetrating brain injury. Brain Res (1993) 628(1-2):271-8. doi:10.1016/0006-8993(93)90964-O

76. Barreto G, Santos-Galindo M, Diz-Chaves Y, Pernia O, Carrero P, Azcoitia I, et al. Selective estrogen receptor modulators decrease reactive astrogliosis in the injured brain: effects of aging and prolonged depletion of ovarian hormones. Endocrinology (2009) 150(11):5010-5. doi:10.1210/ en.2009-0352

77. Ciriza I, Carrero P, Azcoitia I, Lundeen SG, Garcia-Segura LM. Selective estrogen receptor modulators protect hippocampal neurons from kainic acid excitotoxicity: differences with the effect of estradiol. J Neurobiol (2004) 61(2):209-21. doi:10.1002/neu.20043

78. Tripanichkul W, Sripanichkulchai K, Finkelstein DI. Estrogen down-regulates glial activation in male mice following 1-methyl-4-phenyl-1,2,3,6-tetrahydropyridine intoxication. Brain Res (2006) 1084(1):28-37. doi:10.1016/j. brainres.2006.02.029

79. Valles SL, Dolz-Gaiton P, Gambini J, Borras C, Lloret A, Pallardo FV, et al. Estradiol or genistein prevent Alzheimer's disease-associated inflammation correlating with an increase PPAR gamma expression in cultured astrocytes. Brain Res (2010) 1312:138-44. doi:10.1016/j.brainres.2009.11.044

80. Kireev RA, Vara E, Vina J, Tresguerres JA. Melatonin and oestrogen treatments were able to improve neuroinflammation and apoptotic processes in dentate gyrus of old ovariectomized female rats. Age (Dordr) (2014) 36(5):9707. doi:10.1007/s11357-014-9707-3

81. Cerciat M, Unkila M, Garcia-Segura LM, Arevalo MA. Selective estrogen receptor modulators decrease the production of interleukin- 6 and interferon-gamma-inducible protein-10 by astrocytes exposed to inflammatory challenge in vitro. Glia (2010) 58(1):93-102. doi:10.1002/glia.20904

82. Spence RD, Hamby ME, Umeda E, Itoh $\mathrm{N}, \mathrm{Du} \mathrm{S}$, Wisdom AJ, et al. Neuroprotection mediated through estrogen receptor-alpha in astrocytes. Proc Natl Acad Sci U S A (2011) 108(21):8867-72. doi:10.1073/ pnas. 1103833108

83. Guo J, Duckles SP, Weiss JH, Li X, Krause DN. 17Beta-estradiol prevents cell death and mitochondrial dysfunction by an estrogen receptor-dependent mechanism in astrocytes after oxygen-glucose deprivation/ reperfusion. Free Radic Biol Med (2012) 52(11-12):2151-60. doi:10.1016/j. freeradbiomed.2012.03.005

84. De Marinis E, Acaz-Fonseca E, Arevalo MA, Ascenzi P, Fiocchetti M, Marino $\mathrm{M}$, et al. 17Beta-oestradiol anti-inflammatory effects in primary astrocytes require oestrogen receptor beta-mediated neuroglobin up-regulation. $J$ Neuroendocrinol (2013) 25(3):260-70. doi:10.1111/jne.12007

85. Lee E, Sidoryk-Wegrzynowicz M, Farina M, Rocha JB, Aschner M. Estrogen attenuates manganese-induced glutamate transporter impairment in rat primary astrocytes. Neurotox Res (2013) 23(2):124-30. doi:10.1007/ s12640-012-9347-2

86. Sarkaki AR, Khaksari Haddad M, Soltani Z, Shahrokhi N, Mahmoodi M. Time- and dose-dependent neuroprotective effects of sex steroid hormones on inflammatory cytokines after a traumatic brain injury. J Neurotrauma (2013) 30(1):47-54. doi:10.1089/neu.2010.1686
87. Zhang QG, Wang R, Tang H, Dong Y, Chan A, Sareddy GR, et al. Brainderived estrogen exerts anti-inflammatory and neuroprotective actions in the rat hippocampus. Mol Cell Endocrinol (2014) 389(1-2):84-91. doi:10.1016/j. mce.2013.12.019

88. Marriott LK, Hauss-Wegrzyniak B, Benton RS, Vraniak PD, Wenk GL Long-term estrogen therapy worsens the behavioral and neuropathological consequences of chronic brain inflammation. Behav Neurosci (2002) 116(5):902-11. doi:10.1037/0735-7044.116.5.902

89. Nordell VL, Scarborough MM, Buchanan AK, Sohrabji F. Differential effects of estrogen in the injured forebrain of young adult and reproductive senescent animals. Neurobiol Aging (2003) 24(5):733-43. doi:10.1016/ S0197-4580(02)00193-8

90. Cunningham MA, Wirth JR, Freeman LR, Boger HA, Granholm AC, Gilkeson GS. Estrogen receptor alpha deficiency protects against development of cognitive impairment in murine lupus. J Neuroinflammation (2014) 11:171. doi:10.1186/s12974-014-0171-x

91. Ghisletti S, Meda C, Maggi A, Vegeto E. 17Beta-estradiol inhibits inflammatory gene expression by controlling NF-kappaB intracellular localization. Mol Cell Biol (2005) 25(8):2957-68. doi:10.1128/MCB.25.8.2957-2968.2005

92. Sarvari M, Hrabovszky E, Kallo I, Solymosi N, Toth K, Liko I, et al. Estrogens regulate neuroinflammatory genes via estrogen receptors alpha and beta in the frontal cortex of middle-aged female rats. J Neuroinflammation (2011) 8:82. doi:10.1186/1742-2094-8-82

93. Bilbo SD, Tsang V. Enduring consequences of maternal obesity for brain inflammation and behavior of offspring. FASEB J (2010) 24(6):2104-15 doi:10.1096/fj.09-144014

94. Sasaki A, de Vega WC, St-Cyr S, Pan P, McGowan PO. Perinatal high fat diet alters glucocorticoid signaling and anxiety behavior in adulthood. Neuroscience (2013) 240:1-12. doi:10.1016/j.neuroscience.2013.02.044

95. Bellisario V, Panetta P, Balsevich G, Baumann V, Noble J, Raggi C, et al. Maternal high-fat diet acts as a stressor increasing maternal glucocorticoids signaling to the fetus and disrupting maternal behavior and brain activation in C57BL/6J mice. Psychoneuroendocrinology (2015) 60:138-50. doi:10.1016/j. psyneuen.2015.06.012

96. Sasaki A, de Vega W, Sivanathan S, St-Cyr S, McGowan PO. Maternal high-fat diet alters anxiety behavior and glucocorticoid signaling in adolescent offspring. Neuroscience (2014) 272:92-101. doi:10.1016/j. neuroscience.2014.04.012

97. Tannenbaum BM, Brindley DN, Tannenbaum GS, Dallman MF, McArthur MD, Meaney MJ. High-fat feeding alters both basal and stress-induced hypothalamic-pituitary-adrenal activity in the rat. Am J Physiol (1997) 273(6 Pt 1):E1168-77.

98. Shin AC, MohanKumar SM, Sirivelu MP, Claycombe KJ, Haywood JR, Fink GD, et al. Chronic exposure to a high-fat diet affects stress axis function differentially in diet-induced obese and diet-resistant rats. Int J Obes (Lond) (2010) 34(7):1218-26. doi:10.1038/ijo.2010.34

99. Bray GA, Lovejoy JC, Smith SR, DeLany JP, Lefevre M, Hwang D, et al. The influence of different fats and fatty acids on obesity, insulin resistance and inflammation. J Nutr (2002) 132(9):2488-91.

100. Thaler JP, Schwartz MW. Minireview: inflammation and obesity pathogenesis: the hypothalamus heats up. Endocrinology (2010) 151(9):4109-15. doi:10.1210/en.2010-0336

101. Sivanathan S, Thavartnam K, Arif S, Elegino T, McGowan PO. Chronic high fat feeding increases anxiety-like behaviour and reduces transcript abundance of glucocorticoid signalling genes in the hippocampus of female rats. Behav Brain Res (2015) 286:265-70. doi:10.1016/j.bbr.2015.02.036

102. Herman JP, Ostrander MM, Mueller NK, Figueiredo H. Limbic system mechanisms of stress regulation: hypothalamo-pituitary-adrenocortical axis. Prog Neuropsychopharmacol Biol Psychiatry (2005) 29(8):1201-13. doi:10.1016/j. pnpbp.2005.08.006

103. Sapolsky RM, Krey LC, McEwen BS. The neuroendocrinology of stress and aging: the glucocorticoid cascade hypothesis. Endocr Rev (1986) 7(3):284-301. doi:10.1210/edrv-7-3-284

104. Issa AM, Rowe W, Gauthier S, Meaney MJ. Hypothalamic-pituitary-adrenal activity in aged, cognitively impaired and cognitively unimpaired rats. $J$ Neurosci (1990) 10(10):3247-54.

105. Tarcic N, Ovadia H, Weiss DW, Weidenfeld J. Restraint stress-induced thymic involution and cell apoptosis are dependent on endogenous glucocorticoids. J Neuroimmunol (1998) 82(1):40-6. doi:10.1016/S0165-5728(97)00186-0 
106. De Bosscher K, Vanden Berghe W, Haegeman G. The interplay between the glucocorticoid receptor and nuclear factor-kappaB or activator protein-1: molecular mechanisms for gene repression. Endocr Rev (2003) 24(4):488522. doi:10.1210/er.2002-0006

107. Wurtman RJ, Axelrod J. Control of enzymatic synthesis of adrenaline in adrenal medulla by adrenal cortical steroids. J Biol Chem (1966) 241(10):2301-5.

108. Lindqvist A, Mohapel P, Bouter B, Frielingsdorf H, Pizzo D, Brundin P, et al. High-fat diet impairs hippocampal neurogenesis in male rats. Eur J Neurol (2006) 13(12):1385-8. doi:10.1111/j.1468-1331.2006.01500.x

109. Molteni R, Barnard RJ, Ying Z, Roberts CK, Gomez-Pinilla F. A high-fat, refined sugar diet reduces hippocampal brain-derived neurotrophic factor, neuronal plasticity, and learning. Neuroscience (2002) 112(4):803-14. doi:10.1016/S0306-4522(02)00123-9

110. Wu A, Molteni R, Ying Z, Gomez-Pinilla F. A saturated-fat diet aggravates the outcome of traumatic brain injury on hippocampal plasticity and cognitive function by reducing brain-derived neurotrophic factor. Neuroscience (2003) 119(2):365-75. doi:10.1016/S0306-4522(03)00154-4

111. Granholm AC, Bimonte-Nelson HA, Moore AB, Nelson ME, Freeman LR, Sambamurti K. Effects of a saturated fat and high cholesterol diet on memory and hippocampal morphology in the middle-aged rat. J Alzheimers Dis (2008) 14(2):133-45.

112. Ambrogini P, Orsini L, Mancini C, Ferri P, Barbanti I, Cuppini R. Persistently high corticosterone levels but not normal circadian fluctuations of the hormone affect cell proliferation in the adult rat dentate gyrus. Neuroendocrinology (2002) 76(6):366-72. doi:10.1159/000067581

113. Heine VM, Maslam S, Joels M, Lucassen PJ. Prominent decline of newborn cell proliferation, differentiation, and apoptosis in the aging dentate gyrus, in absence of an age-related hypothalamus-pituitary-adrenal axis activation. Neurobiol Aging (2004) 25(3):361-75. doi:10.1016/S0197-4580(03)00090-3

114. Farr SA, Banks WA, Morley JE. Effects of leptin on memory processing. Peptides (2006) 27(6):1420-5. doi:10.1016/j.peptides.2005.10.006

115. Arnold SE, Lucki I, Brookshire BR, Carlson GC, Browne CA, Kazi H, et al. High fat diet produces brain insulin resistance, synaptodendritic abnormalities and altered behavior in mice. Neurobiol Dis (2014) 67:79-87. doi:10.1016/j.nbd.2014.03.011

116. Molteni R, Wu A, Vaynman S, Ying Z, Barnard RJ, Gomez-Pinilla F. Exercise reverses the harmful effects of consumption of a high-fat diet on synaptic and behavioral plasticity associated to the action of brain-derived neurotrophic factor. Neuroscience (2004) 123(2):429-40. doi:10.1016/j. neuroscience.2003.09.020

117. Boitard C, Cavaroc A, Sauvant J, Aubert A, Castanon N, Laye S, et al. Impairment of hippocampal-dependent memory induced by juvenile highfat diet intake is associated with enhanced hippocampal inflammation in rats. Brain Behav Immun (2014) 40:9-17. doi:10.1016/j.bbi.2014.03.005

118. Liu Y, Fu X, Lan N, Li S, Zhang J, Wang S, et al. Luteolin protects against high fat diet-induced cognitive deficits in obesity mice. Behav Brain Res (2014) 267:178-88. doi:10.1016/j.bbr.2014.02.040

119. Kanoski SE, Zhang Y, Zheng W, Davidson TL. The effects of a high-energy diet on hippocampal function and blood-brain barrier integrity in the rat. J Alzheimers Dis (2010) 21(1):207-19. doi:10.3233/JAD-2010-091414

120. Davidson TL, Monnot A, Neal AU, Martin AA, Horton JJ, Zheng W. The effects of a high-energy diet on hippocampal-dependent discrimination performance and blood-brain barrier integrity differ for diet-induced obese and diet-resistant rats. Physiol Behav (2012) 107(1):26-33. doi:10.1016/j. physbeh.2012.05.015

121. Davidson TL, Hargrave SL, Swithers SE, Sample CH, Fu X, Kinzig KP, et al. Inter-relationships among diet, obesity and hippocampal-dependent cognitive function. Neuroscience (2013) 253:110-22. doi:10.1016/j. neuroscience.2013.08.044

122. Mulder M, Blokland A, van den Berg DJ, Schulten H, Bakker AH, Terwel D, et al. Apolipoprotein E protects against neuropathology induced by a high-fat diet and maintains the integrity of the blood-brain barrier during aging. Lab Invest (2001) 81(7):953-60. doi:10.1038/labinvest.3780307

123. Hsu TM, Kanoski SE. Blood-brain barrier disruption: mechanistic links between Western diet consumption and dementia. Front Aging Neurosci (2014) 6:88. doi:10.3389/fnagi.2014.00088

124. Thomas HV, Reeves GK, Key TJ. Endogenous estrogen and postmenopausal breast cancer: a quantitative review. Cancer Causes Control (1997) 8(6):922-8. doi:10.1023/A:1018476631561
125. Prentice R, Thompson D, Clifford C, Gorbach S, Goldin B, Byar D. Dietary fat reduction and plasma estradiol concentration in healthy postmenopausal women. The Women's Health Trial Study Group. J Natl Cancer Inst (1990) 82(2):129-34. doi:10.1093/jnci/82.2.129

126. Heber D, Ashley JM, Leaf DA, Barnard RJ. Reduction of serum estradiol in postmenopausal women given free access to low-fat high-carbohydrate diet. Nutrition (1991) 7(2):137-9.

127. Goldin BR, Adlercreutz H, Gorbach SL, Woods MN, Dwyer JT, Conlon T, et al. The relationship between estrogen levels and diets of Caucasian American and Oriental immigrant women. Am J Clin Nutr (1986) 44(6):945-53.

128. Rose DP, Boyar AP, Cohen C, Strong LE. Effect of a low-fat diet on hormone levels in women with cystic breast disease. I. Serum steroids and gonadotropins. J Natl Cancer Inst (1987) 78(4):623-6.

129. Woods MN, Gorbach SL, Longcope C, Goldin BR, Dwyer JT, Morrill-LaBrode A. Low-fat, high-fiber diet and serum estrone sulfate in premenopausal women. Am J Clin Nutr (1989) 49(6):1179-83.

130. Bagga D, Ashley JM, Geffrey SP, Wang HJ, Barnard RJ, Korenman S, et al. Effects of a very low fat, high fiber diet on serum hormones and menstrual function. Implications for breast cancer prevention. Cancer (1995) 76(12):2491-6. doi:10.1002/1097-0142(19951215)76:12<2491::AIDCNCR2820761213>3.0.CO;2-R

131. James MJ, Gibson RA, Cleland LG. Dietary polyunsaturated fatty acids and inflammatory mediator production. Am J Clin Nutr (2000) 71(1 Suppl):343S-8S.

132. Kelley DS. Modulation of human immune and inflammatory responses by dietary fatty acids. Nutrition (2001) 17(7-8):669-73. doi:10.1016/ S0899-9007(01)00576-7

133. Noble LS, Takayama K, Zeitoun KM, Putman JM, Johns DA, Hinshelwood MM, et al. Prostaglandin E2 stimulates aromatase expression in endometriosis-derived stromal cells. J Clin Endocrinol Metab (1997) 82(2):600-6. doi:10.1210/jcem.82.2.3783

134. Young LR, Kurzer MS, Thomas W, Redmon JB, Raatz SK. Effect of dietary fat and omega- 3 fatty acids on urinary eicosanoids and sex hormone concentrations in postmenopausal women: a randomized controlled feeding trial. Nutr Cancer (2011) 63(6):930-9. doi:10.1080/01635581.2011.589957

135. Scott E, Zhang QG, Wang R, Vadlamudi R, Brann D. Estrogen neuroprotection and the critical period hypothesis. Front Neuroendocrinol (2012) 33(1):85-104. doi:10.1016/j.yfrne.2011.10.001

136. Fan Y, Liu Y, Xue K, Gu G, Fan W, Xu Y, et al. Diet-induced obesity in male C57BL/6 mice decreases fertility as a consequence of disrupted blood-testis barrier. PLoS One (2015) 10(4):e0120775. doi:10.1371/journal.pone.0120775

137. Yan WJ, Mu Y, Yu N, Yi TL, Zhang Y, Pang XL, et al. Protective effects of metformin on reproductive function in obese male rats induced by high-fat diet. $J$ Assist Reprod Genet (2015) 32(7):1097-104. doi:10.1007/s10815-015-0506-2

138. French SA, Jeffery RW. Consequences of dieting to lose weight: effects on physical and mental health. Health Psychol (1994) 13(3):195-212. doi:10.1037/0278-6133.13.3.195

139. Weissman C. The metabolic response to stress: an overview and update. Anesthesiology(1990)73(2):308-27.doi:10.1097/00000542-199008000-00020

140. Mattson MP. Hormesis defined. Ageing Res Rev (2008) 7(1):1-7. doi:10.1016/j. arr.2007.08.007

141. Munck A, Guyre PM, Holbrook NJ. Physiological functions of glucocorticoids in stress and their relation to pharmacological actions. Endocr Rev (1984) 5(1):25-44. doi:10.1210/edrv-5-1-25

142. Yu BP, Chung HY. Stress resistance by caloric restriction for longevity. Ann $N$ Y Acad Sci (2001) 928:39-47. doi:10.1111/j.1749-6632.2001.tb05633.x

143. Mattson MP, Chan SL, Duan W. Modification of brain aging and neurodegenerative disorders by genes, diet, and behavior. Physiol Rev (2002) 82(3):637-72. doi:10.1152/physrev.00004.2002

144. Mattson MP, Duan W, Wan R, Guo Z. Prophylactic activation of neuroprotective stress response pathways by dietary and behavioral manipulations. NeuroRx (2004) 1(1):111-6. doi:10.1602/neurorx.1.1.111

145. Dhurandhar EJ, Allison DB, van Groen T, Kadish I. Hunger in the absence of caloric restriction improves cognition and attenuates Alzheimer's disease pathology in a mouse model. PLoS One (2013) 8(4):e60437. doi:10.1371/ journal.pone.0060437

146. Nelson JF, Karelus K, Bergman MD, Felicio LS. Neuroendocrine involvement in aging: evidence from studies of reproductive aging and caloric restriction. Neurobiol Aging (1995) 16(5):837-43. doi:10.1016/0197-4580(95)00072-M 
147. Armario A, Montero JL, Jolin T. Chronic food restriction and the circadian rhythms of pituitary-adrenal hormones, growth hormone and thyroid-stimulating hormone. Ann Nutr Metab (1987) 31(2):81-7. doi:10.1159/000177254

148. Han ES, Levin N, Bengani N, Roberts JL, Suh Y, Karelus K, et al. Hyperadrenocorticism and food restriction-induced life extension in the rat: evidence for divergent regulation of pituitary proopiomelanocortin RNA and adrenocorticotropic hormone biosynthesis. J Gerontol A Biol Sci Med Sci (1995) 50(5):B288-94. doi:10.1093/gerona/50A.5.B288

149. Klebanov S, Diais S, Stavinoha WB, Suh Y, Nelson JF. Hyperadrenocorticism, attenuated inflammation, and the life-prolonging action of food restriction in mice. J Gerontol A Biol Sci Med Sci (1995) 50(2):B78-82. doi:10.1093/ gerona/50A.2.B78

150. Heiderstadt KM, McLaughlin RM, Wright DC, Walker SE, Gomez-Sanchez CE. The effect of chronic food and water restriction on open-field behaviour and serum corticosterone levels in rats. Lab Anim (2000) 34(1):20-8. doi:10.1258/002367700780578028

151. Han ES, Evans TR, Shu JH, Lee S, Nelson JF. Food restriction enhances endogenous and corticotropin-induced plasma elevations of free but not total corticosterone throughout life in rats. J Gerontol A Biol Sci Med Sci (2001) 56(9):B391-7. doi:10.1093/gerona/56.9.B391

152. Sabatino F, Masoro EJ, McMahan CA, Kuhn RW. Assessment of the role of the glucocorticoid system in aging processes and in the action of food restriction. J Gerontol (1991) 46(5):B171-9. doi:10.1093/geronj/46.5.B171

153. Harper JM, Leathers CW, Austad SN. Does caloric restriction extend life in wild mice? Aging Cell (2006) 5(6):441-9. doi:10.1111/j.1474-9726.2006.00236.x

154. Tomiyama AJ, Mann T, Vinas D, Hunger JM, Dejager J, Taylor SE. Low calorie dieting increases cortisol. Psychosom Med (2010) 72(4):357-64. doi:10.1097/ PSY.0b013e3181d $9523 \mathrm{c}$

155. Villanueva AL, Schlosser C, Hopper B, Liu JH, Hoffman DI, Rebar RW. Increased cortisol production in women runners. J Clin Endocrinol Metab (1986) 63(1):133-6. doi:10.1210/jcem-63-1-133

156. Casper RC, Chatterton RT Jr, Davis JM. Alterations in serum cortisol and its binding characteristics in anorexia nervosa. J Clin Endocrinol Metab (1979) 49(3):406-11. doi:10.1210/jcem-49-3-406

157. Walford RL, Mock D, Verdery R, MacCallum T. Calorie restriction in biosphere 2: alterations in physiologic, hematologic, hormonal, and biochemical parameters in humans restricted for a 2-year period. J Gerontol A Biol Sci Med Sci (2002) 57(6):B211-24. doi:10.1093/gerona/57.6.B211

158. Grayson BE, Hakala-Finch AP, Kekulawala M, Laub H, Egan AE, Ressler IB, et al. Weight loss by calorie restriction versus bariatric surgery differentially regulates the hypothalamo-pituitary-adrenocortical axis in male rats. Stress (2014) 17(6):484-93. doi:10.3109/10253890.2014.967677

159. Morimoto Y, Arisue K, Yamamura Y. Relationship between circadian rhythm of food intake and that of plasma corticosterone and effect of food restriction on circadian adrenocortical rhythm in the rat. Neuroendocrinology (1977) 23(4):212-22. doi:10.1159/000122669

160. Yaktine AL, Vaughn R, Blackwood D, Duysen E, Birt DF. Dietary energy restriction in the SENCAR mouse: elevation of glucocorticoid hormone levels but no change in distribution of glucocorticoid receptor in epidermal cells. Mol Carcinog (1998) 21(1):62-9. doi:10.1002/ (SICI)1098-2744(199801)21:1<62::AID-MC8>3.3.CO;2-8

161. al-Hadramy MS, Zawawi TH, Abdelwahab SM. Altered cortisol levels in relation to Ramadan. Eur J Clin Nutr (1988) 42(4):359-62.

162. Sliman NA, Ajlouni KS, Faisal K. Effect of fasting on some blood hormones in healthy Muslim males. Mutah J Res Stud (1993) 8:91-109.

163. Ben Salem L, B'Chir S, Bchir F, Bouguerra R, Ben Slama C. [Circadian rhythm of cortisol and its responsiveness to ACTH during Ramadan]. Ann Endocrinol (2002) 63(6 Pt 1):497-501. doi:AE-12-2002-63-6-0003-4266-101019-ART8

164. El-Migdadi F, El-Akawi Z, Abudheese R, Bashir N. Plasma levels of adrenocorticotropic hormone and cortisol in people living in an environment below sea level (Jordan Valley) during fasting in the month of Ramadan. Horm Res (2002) 58(6):279-82. doi:10.1159/000066446

165. Faris MA, Kacimi S, Al-Kurd RA, Fararjeh MA, Bustanji YK, Mohammad MK, et al. Intermittent fasting during Ramadan attenuates proinflammatory cytokines and immune cells in healthy subjects. Nutr Res (2012) 32(12):94755. doi:10.1016/j.nutres.2012.06.021

166. Akrami Mohajeri F, Ahmadi Z, Hassanshahi G, Akrami Mohajeri E, Ravari A, Ghalebi SR. Dose Ramadan fasting affects inflammatory responses: evidences for modulatory roles of this unique nutritional status via chemokine network. Iran J Basic Med Sci (2013) 16(12):1217-22.

167. Tam CS, Frost EA, Xie W, Rood J, Ravussin E, Redman LM, et al. No effect of caloric restriction on salivary cortisol levels in overweight men and women. Metabolism (2014) 63(2):194-8. doi:10.1016/j.metabol.2013.10.007

168. Johnstone AM, Faber P, Andrew R, Gibney ER, Elia M, Lobley G, et al. Influence of short-term dietary weight loss on cortisol secretion and metabolism in obese men. Eur J Endocrinol (2004) 150(2):185-94. doi:10.1530/ eje. 0.1500185

169. Sticker LS, Thompson DL Jr, Fernandez JM, Bunting LD, DePew CL. Dietary protein and(or) energy restriction in mares: plasma growth hormone, IGF-I, prolactin, cortisol, and thyroid hormone responses to feeding, glucose, and epinephrine. J Anim Sci (1995) 73(5):1424-32.

170. Glade MJ, Gupta S, Reimers TJ. Hormonal responses to high and low planes of nutrition in weanling thoroughbreds. J Anim Sci (1984) 59(3):658-65.

171. Smith-Swintosky VL, Pettigrew LC, Sapolsky RM, Phares C, Craddock SD, BrookeSM,etal.Metyrapone, aninhibitorofglucocorticoidproduction, reduces brain injury induced by focal and global ischemia and seizures. J Cereb Blood Flow Metab (1996) 16(4):585-98. doi:10.1097/00004647-199607000-00008

172. Aly KB, Pipkin JL, Hinson WG, Feuers RJ, Duffy PH, Lyn-Cook L, et al. Chronic caloric restriction induces stress proteins in the hypothalamus of rats. Mech Ageing Dev (1994) 76(1):11-23. doi:10.1016/0047-6374(94)90002-7

173. Yu ZF, Mattson MP. Dietary restriction and 2-deoxyglucose administration reduce focal ischemic brain damage and improve behavioral outcome: evidence for a preconditioning mechanism. J Neurosci Res (1999) 57(6):830-9. doi:10.1002/(SICI) 1097-4547(19990915)57:6<830::AID-JNR8>3.3.CO;2-U

174. Zatsepina OG, Evgenev MB, Liashchko VN. [Changes in the transcription activity of c-myc genes and heat shock proteins (HSP 70) after incubation of mouse plasmacytoma cells with dexamethasone]. Mol Biol (1990) 24(2):391-5.

175. Lee J, Herman JP, Mattson MP. Dietary restriction selectively decreases glucocorticoid receptor expression in the hippocampus and cerebral cortex of rats. Exp Neurol (2000) 166(2):435-41. doi:10.1006/exnr.2000.7512

176. Vasconcelos AR, Yshii LM, Viel TA, Buck HS, Mattson MP, Scavone C, et al. Intermittent fasting attenuates lipopolysaccharide-induced neuroinflammation and memory impairment. J Neuroinflammation (2014) 11:85. doi:10.1186/1742-2094-11-85

177. MacDonald L, Radler M, Paolini AG, Kent S. Calorie restriction attenuates LPS-induced sickness behavior and shifts hypothalamic signaling pathways to an anti-inflammatory bias. Am J Physiol Regul Integr Comp Physiol (2011) 301(1):R172-84. doi:10.1152/ajpregu.00057.2011

178. MacDonald L, Hazi A, Paolini AG, Kent S. Calorie restriction dose-dependently abates lipopolysaccharide-induced fever, sickness behavior, and circulating interleukin- 6 while increasing corticosterone. Brain Behav Immun (2014) 40:18-26. doi:10.1016/j.bbi.2014.01.005

179. Matsuzaki J, Kuwamura M, Yamaji R, Inui H, Nakano Y. Inflammatory responses to lipopolysaccharide are suppressed in $40 \%$ energy-restricted mice. J Nutr (2001) 131(8):2139-44.

180. Longo VD, Fontana L. Calorie restriction and cancer prevention: metabolic and molecular mechanisms. Trends Pharmacol Sci (2010) 31(2):89-98. doi:10.1016/j.tips.2009.11.004

181. Trainin N. Adrenal imbalance in mouse skin carcinogenesis. Cancer Res (1963) 23:415-9.

182. Belman S, Troll W. The inhibition of croton oil-promoted mouse skin tumorigenesis by steroid hormones. Cancer Res (1972) 32(3):450-4.

183. Mitev Y, Almeida OF, Patchev V. Pituitary-adrenal function and hypothalamic beta-endorphin release in vitro following food deprivation. Brain Res Bull (1993) 30(1-2):7-10. doi:10.1016/0361-9230(93)90033-8

184. Zhu Z, Jiang W, Thompson HJ. An experimental paradigm for studying the cellular and molecular mechanisms of cancer inhibition by energy restriction. Mol Carcinog (2002) 35(2):51-6. doi:10.1002/mc.10073

185. Zhu Z, Jiang W, Thompson HJ. Mechanisms by which energy restriction inhibits rat mammary carcinogenesis: in vivo effects of corticosterone on cell cycle machinery in mammary carcinomas. Carcinogenesis (2003) 24(7):1225-31. doi:10.1093/carcin/bgg077

186. Pashko LL, Schwartz AG. Reversal of food restriction-induced inhibition of mouse skin tumor promotion by adrenalectomy. Carcinogenesis (1992) 13(10):1925-8. doi:10.1093/carcin/13.10.1925 
187. Pashko LL, Schwartz AG. Inhibition of 7,12-dimethylbenz[a] anthracene-induced lung tumorigenesis in $\mathrm{A} / \mathrm{J}$ mice by food restriction is reversed by adrenalectomy. Carcinogenesis (1996) 17(2):209-12. doi:10.1093/ carcin/17.2.209

188. Stewart JW, Koehler K, Jackson W, Hawley J, Wang W, Au A, et al. Prevention of mouse skin tumor promotion by dietary energy restriction requires an intact adrenal gland and glucocorticoid supplementation restores inhibition. Carcinogenesis (2005) 26(6):1077-84. doi:10.1093/carcin/bgi051

189. Akiyama H, Barger S, Barnum S, Bradt B, Bauer J, Cole GM, et al. Inflammation and Alzheimer's disease. Neurobiol Aging (2000) 21(3):383-421. doi:10.1016/ S0197-4580(00)00124-X

190. Fito M, Guxens M, Corella D, Saez G, Estruch R, de la Torre R, et al. Effect of a traditional Mediterranean diet on lipoprotein oxidation: a randomized controlled trial. Arch Intern Med (2007) 167(11):1195-203. doi:10.1001/ archinte.167.11.1195

191. Floyd RA. Neuroinflammatory processes are important in neurodegenerative diseases: an hypothesis to explain the increased formation of reactive oxygen and nitrogen species as major factors involved in neurodegenerative disease development. Free Radic Biol Med (1999) 26(9-10):1346-55. doi:10.1016/ S0891-5849(98)00293-7

192. Teunissen CE, Lutjohann D, von Bergmann K, Verhey F, Vreeling F, Wauters A, et al. Combination of serum markers related to several mechanisms in Alzheimer's disease. Neurobiol Aging (2003) 24(7):893-902. doi:10.1016/ S0197-4580(03)00005-8

193. DeLegge MH, Smoke A. Neurodegeneration and inflammation. Nutr Clin Pract (2008) 23(1):35-41. doi:10.1177/011542650802300135

194. Bruce-Keller AJ, Umberger G, McFall R, Mattson MP. Food restriction reduces brain damage and improves behavioral outcome following excitotoxic and metabolic insults. Ann Neurol (1999) 45(1):8-15. doi:10.1002/1531-8249(199901)45:1<8::AID-ART4>3.3.CO;2-M

195. Arumugam TV, Phillips TM, Cheng A, Morrell CH, Mattson MP, Wan R. Age and energy intake interact to modify cell stress pathways and stroke outcome. Ann Neurol (2010) 67(1):41-52. doi:10.1002/ana.21798

196. Fann DY, Santro T, Manzanero S, Widiapradja A, Cheng YL, Lee SY, et al. Intermittent fasting attenuates inflammasome activity in ischemic stroke. Exp Neurol (2014) 257:114-9. doi:10.1016/j.expneurol.2014.04.017

197. Hatzinger M, Z’Brun A, Hemmeter U, Seifritz E, Baumann F, HolsboerTrachsler E, et al. Hypothalamic-pituitary-adrenal system function in patients with Alzheimer's disease. Neurobiol Aging (1995) 16(2):205-9. doi:10.1016/0197-4580(94)00159-6

198. Goodman Y, Bruce AJ, Cheng B, Mattson MP. Estrogens attenuate and corticosterone exacerbates excitotoxicity, oxidative injury, and amyloid beta-peptide toxicity in hippocampal neurons. J Neurochem (1996) 66(5):1836-44. doi:10.1046/j.1471-4159.1996.66051836.x

199. Pedersen WA, Culmsee C, Ziegler D, Herman JP, Mattson MP. Aberrant stress response associated with severe hypoglycemia in a transgenic mouse model of Alzheimer's disease. J Mol Neurosci (1999) 13(1-2):159-65. doi:10.1385/ JMN:13:1-2:159

200. Peck MD, Babcock GF, Alexander JW. The role of protein and calorie restriction in outcome from Salmonella infection in mice. JPEN J Parenter Enteral Nutr (1992) 16(6):561-5. doi:10.1177/0148607192016006561

201. Dong W, Selgrade MK, Gilmour IM, Lange RW, Park P, Luster MI, et al. Altered alveolar macrophage function in calorie-restricted rats. Am J Respir Cell Mol Biol (1998) 19(3):462-9. doi:10.1165/ajrcmb.19.3.3114

202. Mascarucci P, Taub D, Saccani S, Paloma MA, Dawson H, Roth GS, et al. Cytokine responses in young and old rhesus monkeys: effect of caloric restriction. J Interferon Cytokine Res (2002) 22(5):565-71. doi:10.1089/10799900252982043

203. Jolly CA. Dietary restriction and immune function. J Nutr (2004) 134(8):1853-6.

204. Nayak BN, Friel JK, Rempel CB, Jones PJ. Energy-restricted diets result in higher numbers of CD4+, CD8+, immunoglobulins (A, M, and $G$ ), and CD45RA cells in spleen and CD4+, immunoglobulin A, and CD45RA cells in colonic lamina propria of rats. Nutr Res (2009) 29(7):487-93. doi:10.1016/j. nutres.2009.06.010

205. Patel NV, Finch CE. The glucocorticoid paradox of caloric restriction in slowing brain aging. Neurobiol Aging (2002) 23(5):707-17. doi:10.1016/ S0197-4580(02)00017-9

206. Harvie MN, Pegington M, Mattson MP, Frystyk J, Dillon B, Evans G, et al. The effects of intermittent or continuous energy restriction on weight loss and metabolic disease risk markers: a randomized trial in young overweight women. Int J Obes (Lond) (2011) 35(5):714-27. doi:10.1038/ijo.2010.171

Conflict of Interest Statement: The authors declare that the research was conducted in the absence of any commercial or financial relationships that could be construed as a potential conflict of interest.

Copyright (c) 2016 Vasconcelos, Cabral-Costa, Mazucanti, Scavone and Kawamoto. This is an open-access article distributed under the terms of the Creative Commons Attribution License (CC BY). The use, distribution or reproduction in other forums is permitted, provided the original author(s) or licensor are credited and that the original publication in this journal is cited, in accordance with accepted academic practice. No use, distribution or reproduction is permitted which does not comply with these terms. 